\title{
Coupling hydrodynamic and wave models: first step and sensitivity experiments in the Mediterranean Sea
}

\author{
Emanuela Clementi $^{1}$ (D) Paolo Oddo ${ }^{1,2} \cdot$ Massimiliano Drudi $^{1} \cdot$ Nadia Pinardi $^{3,4}$. \\ Gerasimos Korres $^{5}$ - Alessandro Grandi ${ }^{1}$
}

Received: 19 November 2016 / Accepted: 9 July 2017 / Published online: 29 July 2017

(C) The Author(s) 2017. This article is an open access publication

\begin{abstract}
This work describes the first step towards a fully coupled modelling system composed of an ocean circulation and a wind wave model. Sensitivity experiments are presented for the Mediterranean Sea where the hydrodynamic model NEMO is coupled with the third-generation wave model WaveWatchIII (WW3). Both models are implemented at $1 / 16^{\circ}$ horizontal resolution and are forced by ECMWF $1 / 4^{\circ}$ horizontal resolution atmospheric fields. The models are twoway coupled at hourly intervals exchanging the following fields: sea surface currents and temperature are transferred from NEMO to WW3 by modifying the mean momentum transfer of waves and the wind speed stability parameter, respectively. The neutral drag coefficient computed by WW3 is then passed to NEMO, which computes the surface stress. Five-year (20092013) numerical experiments were carried out in both uncoupled and coupled mode. In order to validate the
\end{abstract}

This article is part of the Topical Collection on the 8th International Workshop on Modeling the Ocean (IWMO), Bologna, Italy, 7-10 June 2016

Responsible Editor: Marco Zavatarelli

Emanuela Clementi

emanuela.clementi@ingv.it

1 Istituto Nazionale di Geofisica e Vulcanologia, INGV, Bologna, Italy

2 Present address: NATO Science and Technology Organization Centre for Maritime Research and Experimentation, La Spezia, Italy

3 Department of Physics and Astronomy, Alma Mater University of Bologna, Bologna, Italy

4 Fondazione Centro Euro-Mediterraneo sui Cambiamenti Climatici, CMCC, Bologna, Italy

5 Hellenic Centre for Marine Research Institute of Oceanography, HCMR, Anavyssos, Greece modelling system, numerical results were compared with coastal and drifting buoys and remote sensing data. The results show that the coupling of currents with waves improves the representation of the wave spectrum. However, the wave-induced drag coefficient shows only minor improvements in NEMO circulation fields, such as temperature, salinity, and currents.

Keywords Mediterranean Sea $\cdot$ Hydrodynamics $\cdot$ Waves . Numerical modelling $\cdot$ NEMO $\cdot$ WaveWatch3

\section{Introduction}

Wind-wave-current coupling is of growing interest since it has long been recognized that these interactions control the momentum and energy exchange between the atmosphere and the ocean, and need to be better understood and resolved. The currents are driven by surface wind stresses that in turn are a function of the sea state. On the other hand, the sea state depends on the wind stress and the currents. These are complicated feedback mechanisms which can be modelled by coupling hydrodynamic and wave models which to date have been developed separately.

Model coupling can be achieved at various levels of complexity. A complete review of wind-wave-current interactions processes can be found in Jonsson (1990) and more recently in Cavaleri et al. (2012). The present work focuses on wave and current modifications due to interactions of waves with surface currents, and the wind speed correction due to a stability parameter that depends on air-sea temperature differences (Tolman 2002), and to the surface drag coefficient for currents which takes into account the wave effects.

Wind generated waves are affected when they interact with currents since wave characteristics such as wavelength, amplitude, frequency, and direction are modified due to the 
Doppler shift. For the wave frequency, the shift can be written as follows:

$\omega=\sigma+\mathbf{K} \cdot \mathbf{U}_{\mathbf{c}}$

where $\omega$ is the absolute wave frequency, $\mathbf{K}$ is the wavenumber vector, $\mathbf{U}_{\mathbf{c}}$ is the surface current velocity vector, and $\sigma$ is the wave intrinsic frequency (Phillips 1977). The degree to which the Doppler shift modifies the surface waves depends on the current speed relative to the wave propagation speed, which means that slow propagating waves are most affected by currents. High winds and strong currents can lead to wave merging, thus, creating single exceptionally large waves (rogue waves), waves travelling in the area of strong opposite currents may become short and steep (being potentially hazardous for navigation), and wave blocking or breaking may occur in the case of strong opposite currents against waves.

The difference between sea surface temperature (SST) and air temperature affects the stability of the lower atmosphere and thus the wind velocity structure. Tolman (2002) formulated a stability correction by replacing the wind speed with an effective wind speed so that the wave growth reproduces Kahma and Calkoen (1992) stable and unstable wave growth curves.

The atmospheric wind stress is the main driving force for the hydrodynamic currents that are produced by internal turbulent stresses. The wind stress depends on the wind speed and sea roughness that arises from surface waves; thus, ocean current energy input depends on surface waves. The surface wind stress, $\tau$, is parameterized following the bulk formula:

$\tau=\rho_{a} C_{D}\left|\mathbf{U}_{10}-\mathbf{U}_{\mathrm{c}}\right|\left(\mathbf{U}_{10}-\mathbf{U}_{\mathrm{c}}\right)$

where $\rho_{a}$ is the air density, $C_{D}$ is the surface drag coefficient, $\mathbf{U}_{\mathbf{1 0}}$ is the atmospheric $10 \mathrm{~m}$ wind speed, and $\mathbf{U}_{\mathrm{c}}$ is the surface current. Uncertainties in wind stress calculations arise from wind model resolution and depend on wind speed and direction and from the specification of the drag coefficient, which quantifies how much the surface winds are slowed down because of surface roughness due to waves. Several authors have proposed different parameterizations for the drag coefficient usually based on local observations and the function of wind speed and air-sea temperature difference (Wu 1980, 1982; Hellerman and Rosenstein 1983; Large 2006). However, for more realistic computations, a wave model should provide the estimate of the drag as a function of the wave spectrum.

In this first step approach to couple wind waves and currents, all three abovementioned processes, consisting in feeding the wave model with sea surface temperature and surface currents computed by the hydrodynamic model and returning a neutral wind drag coefficient to the latter, were selected in order to develop the model coupling between a hydrodynamic model and a wave model forced by winds from an atmospheric analysis and forecasting model. The paper concentrates on the process of momentum exchange between wind waves and currents in the Mediterranean Sea. For a full coupling between waves and currents, the hydrodynamic equations should make use of Stokes Drift velocities, sea-state-dependent momentum flux, a parameterization of wave-induced vertical mixing, and include coastal radiation stresses or vortex force term in the hydrodynamic model equations (Mellor 2003, 2008, 2011; McWilliams et al. 2004; Rascle 2007; Ardhuin et al. 2008; Bennis et al. 2011; Uchiyama et al. 2010; Kumar et al. 2012; Michaud et al. 2012; Breivik et al. 2014, 2015, Alari et al. 2016, Staneva et al. 2017); however, this is out of the scope of the development of the present work. By excluding these processes, surface wave effects are not accounted in the ocean model primitive equations; moreover, breaking waves effect in enhancing turbulence is not performed nor wave absorbed (or released) stress is directly accounted.

The coupled modelling system is composed of the ocean circulation model NEMO (Madec et al. 1998; Madec 2008), the third-generation wave model WaveWatchIII (WW3, Tolman 2009), and the ECMWF analysis wind forcing. NEMO and WW3 are implemented in the Mediterranean Sea with $1 / 16^{\circ}$ horizontal resolution (Fig. 1). The ECMWF forcing is considered at $1 / 4^{\circ}$ resolution for $10 \mathrm{~m}$ wind velocities and $2 \mathrm{~m}$ air temperatures. The models are two-way coupled by exchanging the following fields at hourly intervals: the sea surface currents and air-sea temperature differences from NEMO to WW3 for the wave refraction and the wind speed stability parameter calculation, respectively. The neutral drag coefficient, computed by WW3, is then passed to NEMO which determines the turbulent part of the surface wind stress following Large and Yeager (2004) and Large (2006), as explained in Appendix 3. Such coupling is fairly new for semi-enclosed seas such as the Mediterranean Sea, and impacts need to be quantified in order to improve current and wave forecasting.

The effect of wave-dependent drag coefficient was analyzed in Mastenbroek et al. (1993) showing improvements by modelling surge heights in the North Sea when the wavedependent drag is taken into account instead of a standard Smith and Banke (1975) stress relation. Other works in the Baltic Sea (Alari et al. 2016) and the North Sea (Staneva et al. 2017) show a coupling approach previously implemented by Breivik et al. $(2014,2015)$ consisting in coupling the wave model to the circulation model modified in order to include the Stokes-Coriolis effect and both the sea-state-dependent momentum and energy fluxes. These works show a pronounced effect due to wave coupling on the vertical temperature distribution and on meso-scale events as well as an improved skill in the predicted sea level and currents during storm events. Moreover, in the Mediterranean basin, Lionello et al. (2003) investigated the importance to couple the wave and ocean models with an atmospheric model analyzing air-sea interface fields on a short time scale range for regional meteorological prediction. 


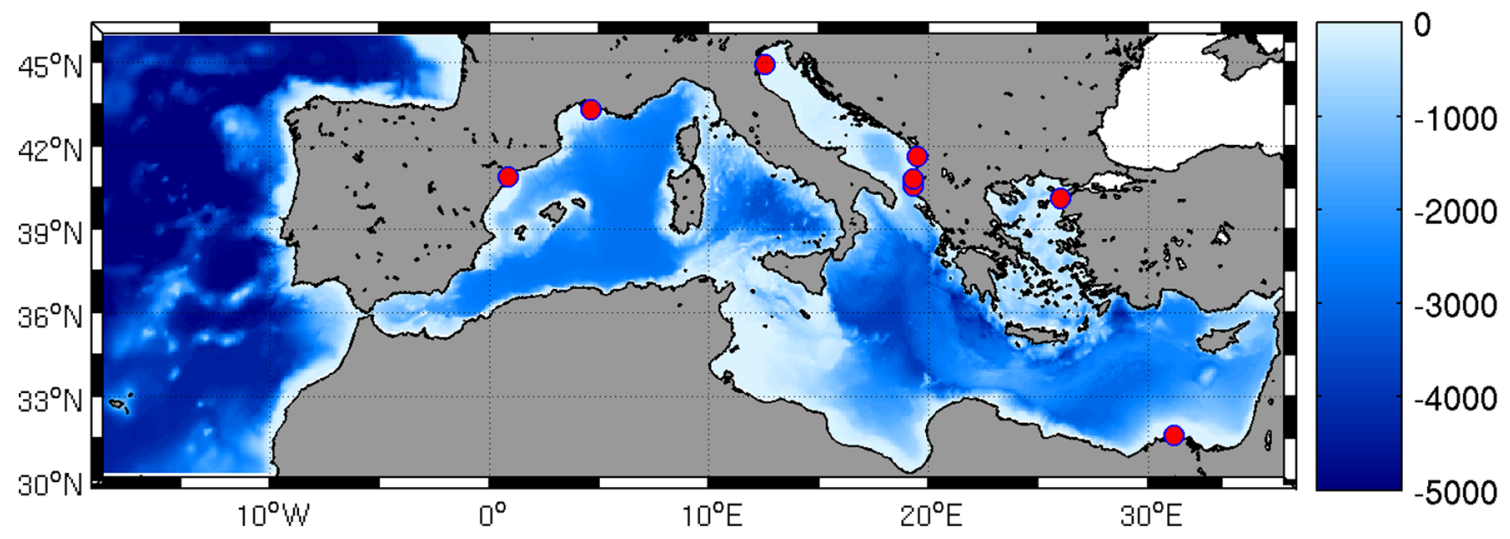

Fig. 1 Mediterranean model domain, bathymetry [m] and river positions (red circles)

The performance of the wave model in the present work is evaluated by comparing numerical results with buoy measurements and altimeter data for satellite significant wave height, mean, and peak wave periods. The performance of the hydrodynamic model is assessed by comparing sea surface currents with coastal buoy observations, model SST with satellite estimates, and vertical temperature and salinity model profiles with ARGO float observations.

The paper is organized as follows. Section 2 presents the model system and the coupling strategy. Section 3 illustrates the numerical experiment design and setup. Section 4 shows the numerical model results and comparison with observations, and in Sect. 5, the conclusions are given.

\section{The model system}

The model system presented in this work is a two-way coupled hydrodynamic circulation model with a thirdgeneration spectral wind wave model as described in the following sections.

\subsection{The atmospheric forcing fields}

ECMWF 6-hourly operational analysis fields were used to force both wave and hydrodynamic models for the 5-year experimental time period 2009-2013. The ECMWF system that produced the atmospheric forcing fields is the IFS (Integrated Forecast System, http://www.ecmwf.int/en/ forecasts/documentation-and-support/changes-ecmwf-model) at $1 / 4^{\circ}$ horizontal resolution and 91 vertical levels.

The meteorological fields of interest were as follows: meridional and zonal components of the velocity field at a $10-\mathrm{m}$ height, air temperature at $2 \mathrm{~m}$, dew point temperature at $2 \mathrm{~m}$, mean sea level atmospheric pressure, and cloud cover. All fields were linearly interpolated to the hydrodynamic and wave model time steps of $600 \mathrm{~s}$.

\subsection{The wave model: WaveWatchIII (WW3)}

The wave model used in the simulations is the thirdgeneration spectral WaveWatchIII model version 3.14 (Tolman 2009), hereafter denoted as WW3. The model solves the wave action balance equation written for a Cartesian grid as follows:

$\frac{\partial}{\partial t} N+\nabla_{x} \cdot \dot{x} N+\frac{\partial}{\partial k} \dot{k} N+\frac{\partial}{\partial \theta} \dot{\theta} N=\frac{S}{\sigma}$

where $N(k, \theta ; \mathbf{x}, t)$ is the wave action density spectrum defined as the variance density spectrum divided by the intrinsic frequency $\sigma, \theta$ is the wave direction, $k$ is the wavenumber, $\mathbf{x}=(x, y)$ is the position vector, $\boldsymbol{x}$ is the wave group velocity vector, $t$ is time, and $S(k, \theta ; \mathbf{x}, t)$ represents the net effect of source and sink terms.

Equation 3 describes the evolution, in a slowly varying depth domain, of a 2D ocean wave spectrum where individual spectral components satisfy the linear wave theory locally.

The source function $S$ on the right-hand side of Eq. 3, is a superposition of wind input source term $S_{\text {in }}$ representing the momentum and energy transfer from air to ocean waves, the wave dissipation due to white-capping $S_{d s}$, and the nonlinear transfer by resonant four-wave interactions $S_{n l}$ :

$S=S_{i n}+S_{d s}+S_{n l}$

In our application, WW3 was implemented following WAM Cycle4 model physics (Gunther et al. 1993). Wind input and dissipation terms are based on Janssen's quasilinear theory of wind-wave generation (Janssen 1989, 1991): the surface waves extract momentum from the air flow and therefore the stress in the surface layer depends both on the wind speed and the wave-induced stress. The dissipation source term was based on Hasselmann's (1974) white-capping theory according to Komen et al. (1984). The nonlinear wave-wave interaction was modelled using 
the discrete interaction approximation (DIA, Hasselmann et al. 1985, Hasselmann and Hasselmann 1985).

When waves interact with surface currents provided by the hydrodynamic model, the propagation velocity in the various phase spaces can be written as follows:

$\dot{x}=c_{g}+\boldsymbol{U}_{c}$

$\dot{k}=-\left(\frac{\partial}{\partial d} \sigma\right)\left(\frac{\partial}{\partial s} d\right)-\mathbf{K} \cdot \frac{\partial}{\partial s} \boldsymbol{U}_{c}$

$\dot{\theta}=-\frac{1}{k}\left[\left(\frac{\partial}{\partial d} \sigma\right)\left(\frac{\partial}{\partial m} d\right)-\boldsymbol{K} \cdot \frac{\partial}{\partial m} \boldsymbol{U}_{c}\right]$

where $\mathbf{c}_{g}$ is the wave propagation velocity vector, $d$ is water depth, $s$ and $m$ are the directions, respectively, along and perpendicular to the wave direction.

The wave model was implemented in the Mediterranean Sea (Fig. 1) considering closed boundaries in the Atlantic Sea, which is a fairly good approximation for the Mediterranean Sea. This is because the occasional propagation of Atlantic swell through the Gibraltar Straits only affects the western part of the Alboran Sea.

\subsection{The hydrodynamic model: NEMO}

The NEMO model version 3.4 (Nucleus for European Modelling of the Ocean, Madec 2008) was used as the hydrodynamic component of our coupled system. The NEMO code solves the primitive equations (derived assuming the hydrostatic and the incompressible approximations), and here, we used the linear free surface formulation solved by the time-splitting technique; thus, the external gravity waves are explicitly resolved. Additionally, the atmospheric pressure effect was introduced in the model dynamics (Oddo et al. (2014) describes the
NEMO implementation with time-splitting and atmospheric pressure effect in the Mediterranean Sea). Figure 1 shows the bathymetry, the river positions (red circles), and the model domain, which extends into the Atlantic Ocean. Lateral boundary conditions in the Atlantic are open and nested into the monthly mean climatological fields computed from 10-year daily output of the $1 / 4^{\circ}$ global model (Drevillon et al. 2008); the nesting details are given in Oddo et al. (2009). Seven rivers are considered as volume inputs: Ebro, Rhone, Po, Vjose, Seman, Bojana, and Nile, and the Dardanelles Strait is closed but is considered as net volume input through a river-like parameterization.

The NEMO configuration parameters can be found in Appendix 2. The advection scheme for active tracers, temperature and salinity, is a mixed upstream/MUSCL (Monotonic Upwind Scheme for Conservation Laws, Van Leer 1979), originally implemented by Estubier and Lévy (2000) and modified by Oddo et al. (2009). The vertical diffusion and viscosity terms are a function of the Richardson number as parameterized by Pacanowsky and Philander (1981).

The model interactively computes air-surface fluxes of momentum, mass, and heat. The bulk formulae implemented are described in Pettenuzzo et al. (2010) and are currently used in the Mediterranean operational system (Tonani et al. 2015). A detailed description of other specific features of the model implementation can be found in Oddo et al. $(2009,2014)$.

\subsection{Model coupling}

The coupling between wave and circulation models is achieved through an hourly exchange of instantaneous
Fig. 2 The coupling mechanism between WW3 and NEMO. When the simulation starts, models exchange information after the first time step (10 $\mathrm{min})$, then communicate every hour. NEMO sends air-sea temperature differences $(\Delta T)$ and current fields $(U, V)$ to WW3, while WW3 sends the neutral drag coefficient $\left(C_{D n}\right)$ to NEMO

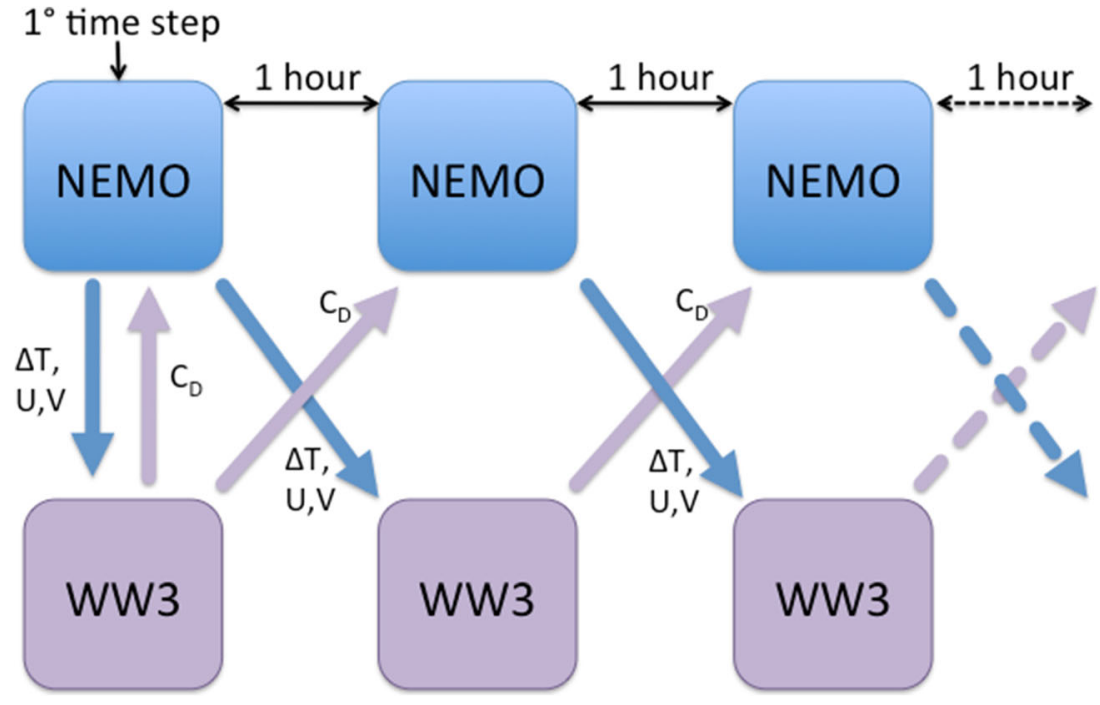


Table 1 List of numerical experiments carried out and simulation period

\begin{tabular}{lll}
\hline Experiment & Description & $\begin{array}{l}\text { Simulation } \\
\text { period }\end{array}$ \\
\hline EXP1 & WW3 standalone (not coupled with NEMO) & 2009-2013 \\
EXP2 & NEMO standalone (not coupled with WW3) & $2009-2013$ \\
EXP3 & WW3 and NEMO coupled every hour as & $2009-2013$ \\
& detailed in Sect. 2.4 & \\
EXP4 & WW3 and NEMO coupled every hour as in & 2010 \\
& $\begin{array}{l}\text { EXP3 but without exchanging air-sea } \\
\text { temperature difference fields }\end{array}$ & \\
& &
\end{tabular}

fields of sea surface currents from NEMO to WW3, airsea temperature differences computed by NEMO are used for including their effects on the wave generation, and the neutral drag coefficient evaluated from WW3 is passed to NEMO. Surface currents and sea surface temperature from NEMO are at $1.5-\mathrm{m}$ depth, and no additional interpolation is carried out for the coupling as both models share exactly the same computational grid. A sketch of the coupling mechanism is represented in Fig. 2.

In the first part of the coupling, the effects of surface currents on waves are taken into account as specified in Eqs. 5-7.

The second part of the coupling is related to the model underestimation of deep-ocean wave growth and the effects of stability on the growth rate of waves as identified by Kahma and Calkoen (1992), which should be explicitly included in the parameterization of the source terms. Instead of correcting the source terms directly, Tolman (2002) proposes using a wind speed correction. The air-sea temperature difference is used to evaluate a stability parameter, $S T$, which is written as follows:

$S T=\left(\frac{h_{g}}{U_{h}^{2}} \frac{T_{a}-T_{s}}{T_{0}}\right)$

where $U_{h}$ and $T_{a}$ are the wind speed and air temperature at height $h$, and $T_{S}$ and $T_{0}$ are the surface and reference temperature, respectively.

An effective wind speed, $\mathbf{U}_{\mathbf{e}}$, is used:

$\mathbf{U}_{\mathrm{e}}=\mathbf{U}_{10}\left(\frac{c_{0}}{1 \pm c_{1} \tanh \left[ \pm c_{2}\left(S T-S T_{0}\right)\right]}\right)^{1 / 2}$

where $\mathbf{U}_{\mathbf{1 0}}$ is the wind speed at $10 \mathrm{~m}$ derived from the ECMWF model output. Values of $c_{0}, c_{1}, c_{2}$, and $S T_{0}$ are set, respectively, to $1.4,0.1,150$, and -0.01 default values, according to Tolman (2002), and the plus or minus sign is the same as $\left(S T-S T_{0}\right)$.

The third part of the coupling consists in the transfer of the wind neutral drag coefficient from the wave model to the hydrodynamics. In the wave model, the neutral wind drag coefficient is computed by the WW 3 model

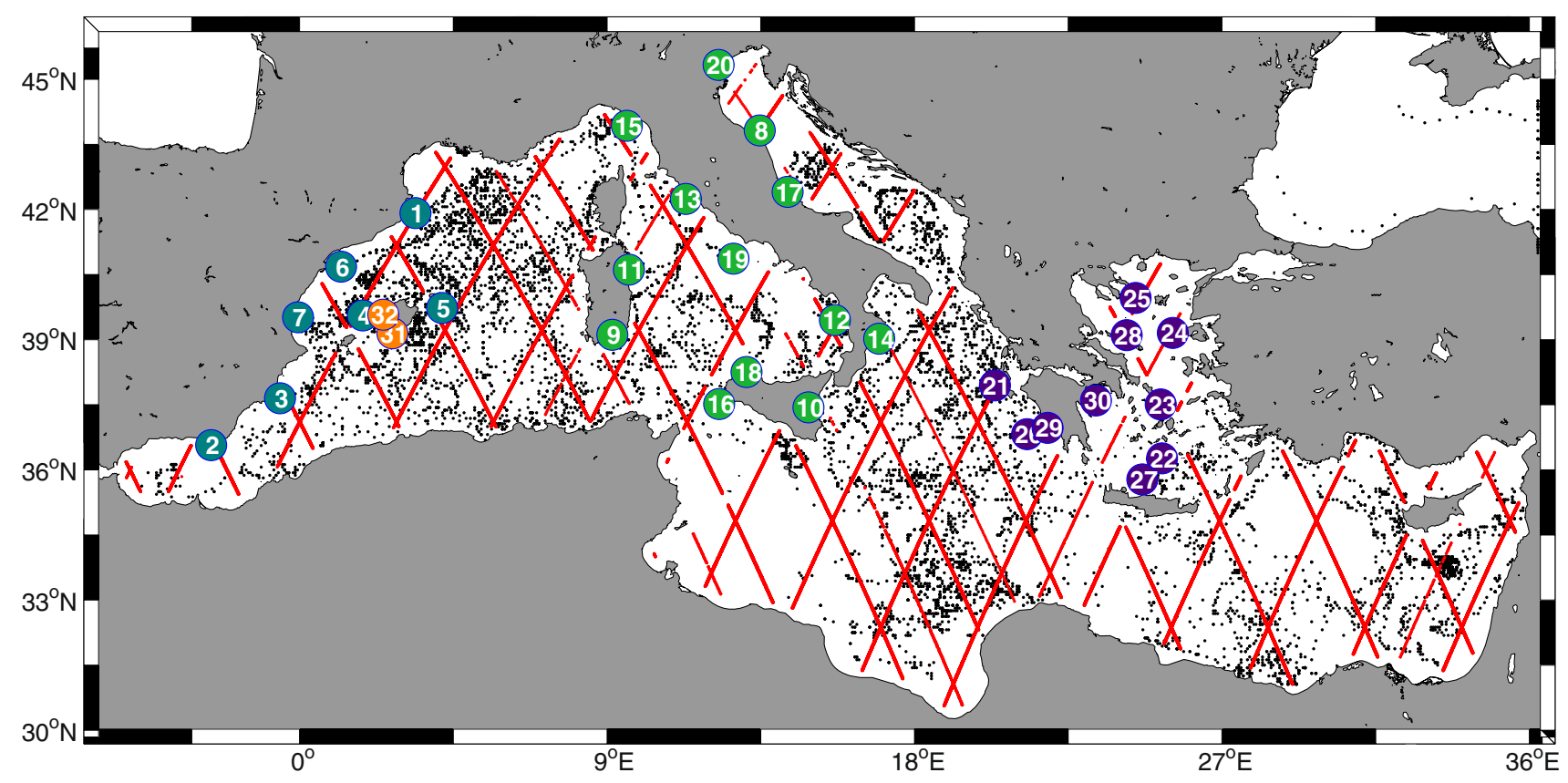

Fig. 3 Networks of measuring stations, satellite tracks, and ARGO profile locations used to validate numerical results. Numbered circles represent coastal buoys (Appendix 1, Table 9) measuring wave and current data (data originators: Puertos de L'Estado, ES (cyan); ISPRA,
IT (green); HCMR, GR (purple), and CSIC, ES (orange)); buoy numbers are listed in Table 9. Red dots indicate the altimetry dataset measuring wave characteristics. Black dots indicate the ARGO profiler positions 
formulation based on the quasi-linear theory of windwave generation developed by Janssen $(1989,1991)$ and based on Miles (1957). According to this theory the neutral drag coefficient $\left(C_{D n}\right)$ depends on the effective roughness length and thus on the sea state through the waveinduced stress estimated from the wave spectra.

$C_{D n}=\left(\frac{\kappa}{\log \left(z_{u} / z_{0}\right)}\right)^{2}$

where $z_{u}$ is the height at which the wind is specified ( $10 \mathrm{~m}$ in the present work), $\mathrm{k}=0.4$ is the von Karman constant, and $z_{0}$ is the roughness length modified by the wave-supported stress $\tau_{w}$ as follows:

$z_{0}=\frac{\alpha_{0} \tau}{\sqrt{1-\tau_{w} / \tau}}$

where $\alpha_{0}$ is set to 0.01 . The neutral drag coefficient (Eq. 10) is transferred to the circulation model where it is used to estimate the turbulent drag coefficient following Large and Yeager (2004) and Large (2006), as described in Appendix 3. The full wind stress for the currents is evaluated using Eq. 2 with the drag coefficient given by Eq. 23 .
Fig. 4 Scatter plot comparing buoy measurements with uncoupled (left, EXP1) and coupled (right, EXP3) model results in terms of: significant wave height $H S(\mathbf{a}, \mathbf{b})$, mean period $T M(\mathbf{c}, \mathbf{d})$, and peak period $T P(\mathbf{e}, \mathbf{f})$. Black dashed lines represent the best-fit (1:1); red and blue dashed lines are the buoy-uncoupled and buoycoupled model data fit, respectively
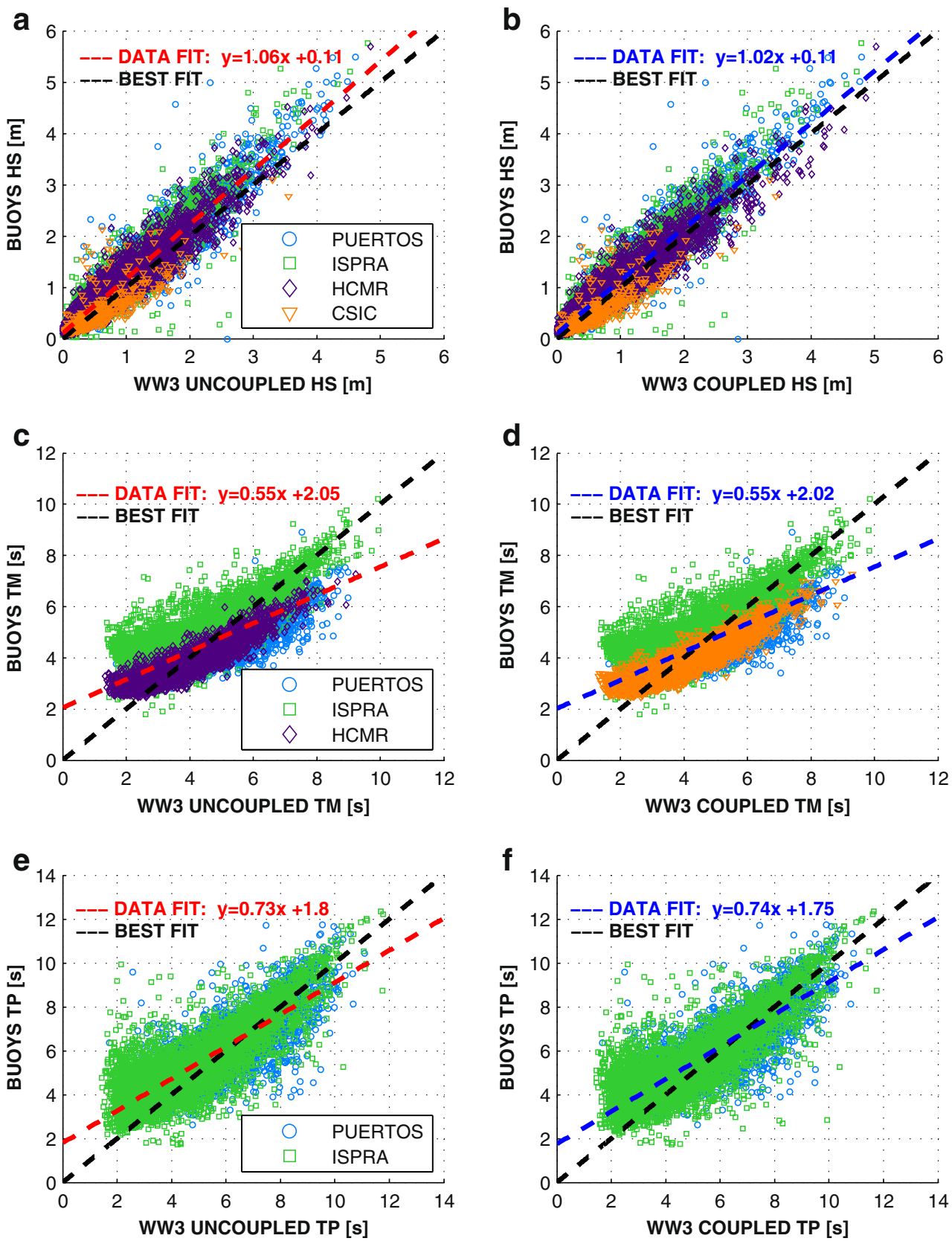

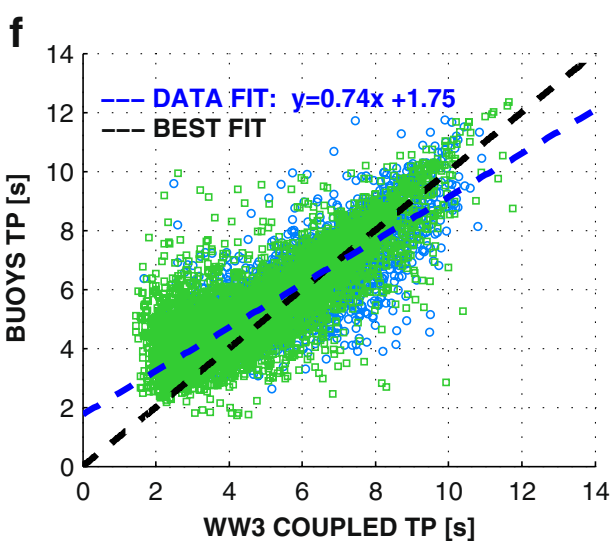


Table 2 Statistics evaluated by comparing buoy measurements and model results in terms of wave height (HS), mean period (TM), and peak period $(T P)$ for uncoupled (EXP1) and coupled (EXP3) wave models

\begin{tabular}{|c|c|c|c|c|c|c|}
\hline Metric & $\begin{array}{l}H S[\mathrm{~m}] \\
\text { EXP1 }\end{array}$ & $\begin{array}{l}H S[\mathrm{~m}] \\
\text { EXP3 }\end{array}$ & $\begin{array}{l}T M[\mathrm{~s}] \\
\mathrm{EXP} 1\end{array}$ & $\begin{array}{l}T M[\mathrm{~s}] \\
\text { EXP3 }\end{array}$ & $\begin{array}{l}T P[\mathrm{~s}] \\
\text { EXP1 }\end{array}$ & $\begin{array}{l}T P[\mathrm{~s}] \\
\text { EXP3 }\end{array}$ \\
\hline Mean & 0.695 & 0.723 & 4.131 & 4.157 & 5.143 & 5.149 \\
\hline$C I$ & $\begin{array}{l}+0.006 \\
-0.006\end{array}$ & $\begin{array}{l}+0.006 \\
-0.007\end{array}$ & $\begin{array}{l}+0.015 \\
-0.014\end{array}$ & $\begin{array}{l}+0.013 \\
-0.014\end{array}$ & $\begin{array}{l}+0.022 \\
-0.022\end{array}$ & $\begin{array}{l}+0.023 \\
-0.021\end{array}$ \\
\hline Bias & -0.152 & -0.124 & -0.207 & -0.172 & -0.454 & -0.435 \\
\hline$C I$ & $\begin{array}{l}+0.002 \\
-0.002\end{array}$ & $\begin{array}{l}+0.002 \\
-0.002\end{array}$ & $\begin{array}{l}+0.011 \\
-0.011\end{array}$ & $\begin{array}{l}+0.011 \\
-0.011\end{array}$ & $\begin{array}{l}+0.014 \\
-0.013\end{array}$ & $\begin{array}{l}+0.013 \\
-0.015\end{array}$ \\
\hline RMSE & 0.256 & 0.236 & 0.901 & 0.887 & 1.047 & 1.023 \\
\hline$C I$ & $\begin{array}{l}+0.004 \\
-0.004\end{array}$ & $\begin{array}{l}+0.004 \\
-0.003\end{array}$ & $\begin{array}{l}+0.009 \\
-0.010\end{array}$ & $\begin{array}{l}+0.009 \\
-0.010\end{array}$ & $\begin{array}{l}+0.018 \\
-0.018\end{array}$ & $\begin{array}{l}+0.018 \\
-0.017\end{array}$ \\
\hline$S T D N$ & 0.896 & 0.931 & 1.38 & 1.38 & 1.15 & 1.14 \\
\hline$R$ & 0.95 & 0.95 & 0.76 & 0.77 & 0.84 & 0.84 \\
\hline
\end{tabular}

\section{Numerical experiment design and validation data sets}

Three numerical experiments were carried out for the period January 2009 to December 2013, and a shorter experiment (year 2010) was also performed to evaluate model coupling without wind corrections. Both wave and current models were defined on the $1 / 16^{\circ}$ (about 6-7 km) grid, and the NEMO vertical resolution was defined by 72 unevenly spaced z-levels using partial cells. For the wave model, the spectral discretization was achieved through 30 frequency bins ranging from $0.05 \mathrm{~Hz}$ (corresponding to a period of $20 \mathrm{~s}$ ) to $0.79 \mathrm{~Hz}$ (corresponding to a period of about $1.25 \mathrm{~s}$ ) and 24 equally distributed directional bins $\left(15^{\circ}\right.$ directional increment). The numerical experiments are set as follows and listed in Table 1:

- EXP1: WW3 uncoupled. The wave model is a standalone model that does not use sea surface currents and temperature derived from the circulation model. This means that no wave-current interactions (refraction of waves due to currents) take place, and no wind correction due to air-sea temperature differences is included.

- EXP2: NEMO uncoupled. The hydrodynamic model is uncoupled, and the turbulent drag coefficient is calculated using the Hellerman and Rosenstein (1983) formulation.

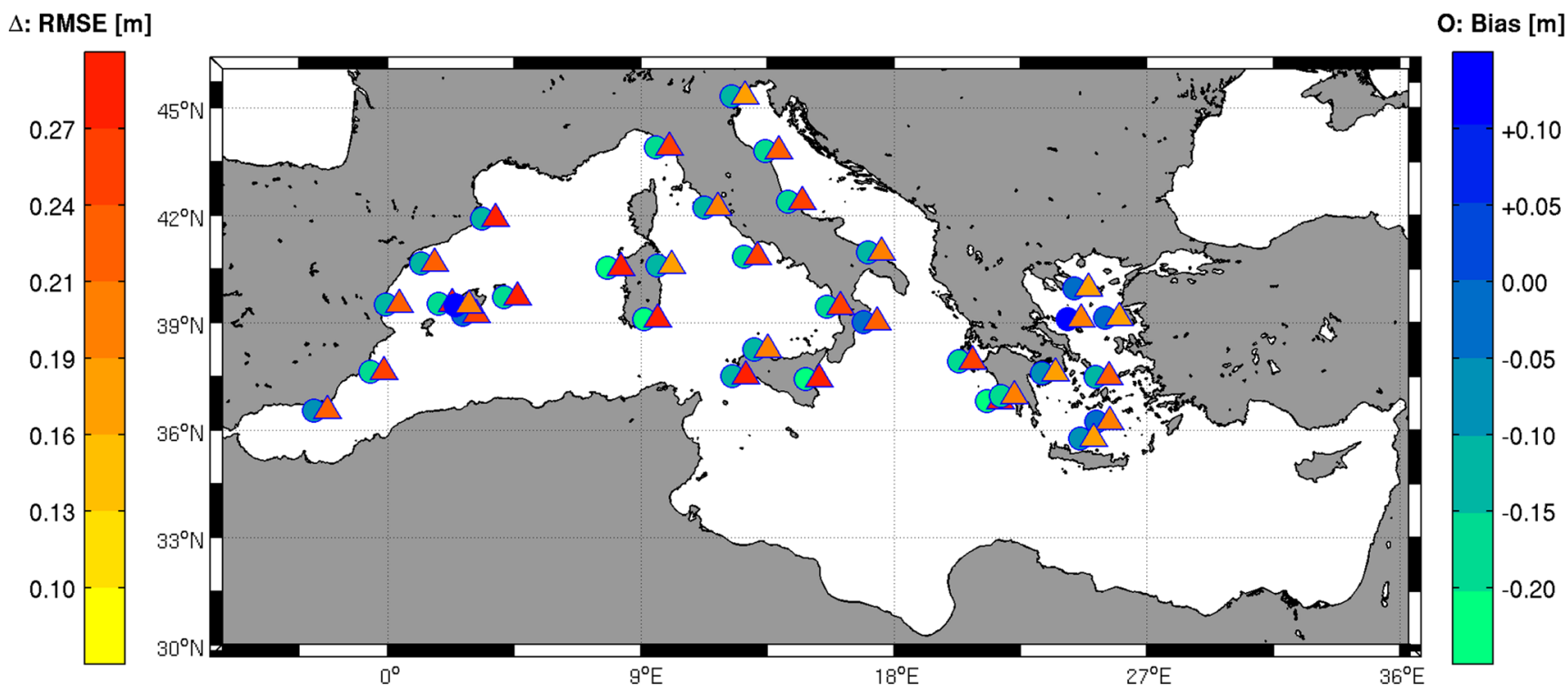

Fig. 5 Significant wave height RMSE (triangles) and Bias (circles) from the buoy data evaluated for the coupled model (EXP3). Colors represent the metric magnitude (left: RMSE from yellow to red; right: Bias from green to blue) 
- EXP3: WW3-NEMO coupled. The two models are two-way coupled by hourly exchanging parameters as described in Sect. 2.4 and depicted in Fig. 2.

- EXP4: WW3-NEMO coupled as in EXP3 but WW3 does not receive air-sea temperature difference fields from NEMO, which means that no wind correction is performed.

\subsection{Observational data sets for validation}

Four sets of data were used to evaluate the accuracy of the model results, i.e., moored buoys in situ measurements, Jason2 along track significant wave height, satellite-derived SST, and ARGO profiles. Figure 3 shows the location of the data sets in the study period 2009-2013.
Fig. 6 Daily averages of significant wave height for the years: 2009 (a), 2010 (b), 2011 (c), 2012 (d), and 2013 (e) at the Valencia buoy. Black lines represent buoy data, red dashed line corresponds to WW3 uncoupled model (EXP1), and blue dashed line refers to WW3NEMO coupled model (EXP3). Bias and RMSE statistics are listed in the figure with the corresponding $C I$ for each year
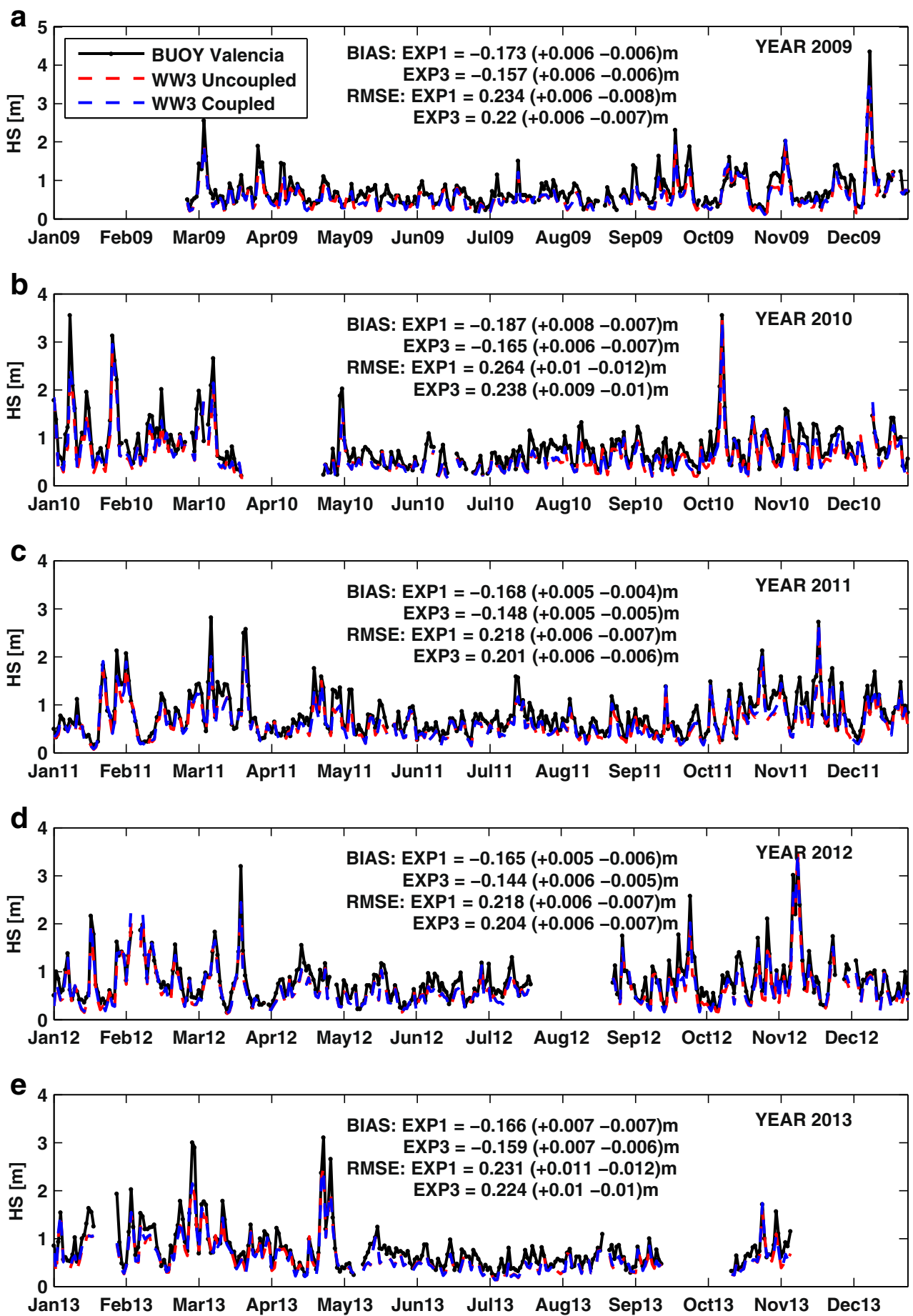
The first source of data consists of daily averages of in situ observations derived from a fixed buoy network (http://calval.bo.ingv.it/). Figure 3 shows the spatial buoy locations, and their name, position, and corresponding networks are listed in Table 9 (Appendix 1).

The second set of data is composed of satellite altimeter-derived wave heights from OSTM/Jason-2. The recommended calibrated significant wave height data (with corrections applied to the altimeter $1 \mathrm{~Hz}$ estimated values) were used.

The satellite sea surface temperature daily gap-free maps (L4) are used at $1 / 16^{\circ}$ horizontal resolution over the Mediterranean Sea (Buongiorno Nardelli et al. 2013). These data were made available through the CMEMS (Copernicus Marine Environment Monitoring Service) catalogue (http:// marine.copernicus.eu/web/69-interactive-catalogue.php).
Fig. 7 Scatter plots of significant wave height $(H S)$ comparison between Jason2 satellite data and numerical results for 2010 to 2013. Left panels (a, c, e, $\mathbf{g})$ represent WW3 uncoupled model results (EXP1); right plots $(\mathbf{b}, \mathbf{d}, \mathbf{f}$, h) show the coupled model (EXP3) significant wave height results. Dot colors refer to the data probability density; black dashed line represents the best-fit (1:1) line; solid red and blue lines show the satellite-uncoupled and coupled model data fit, respectively
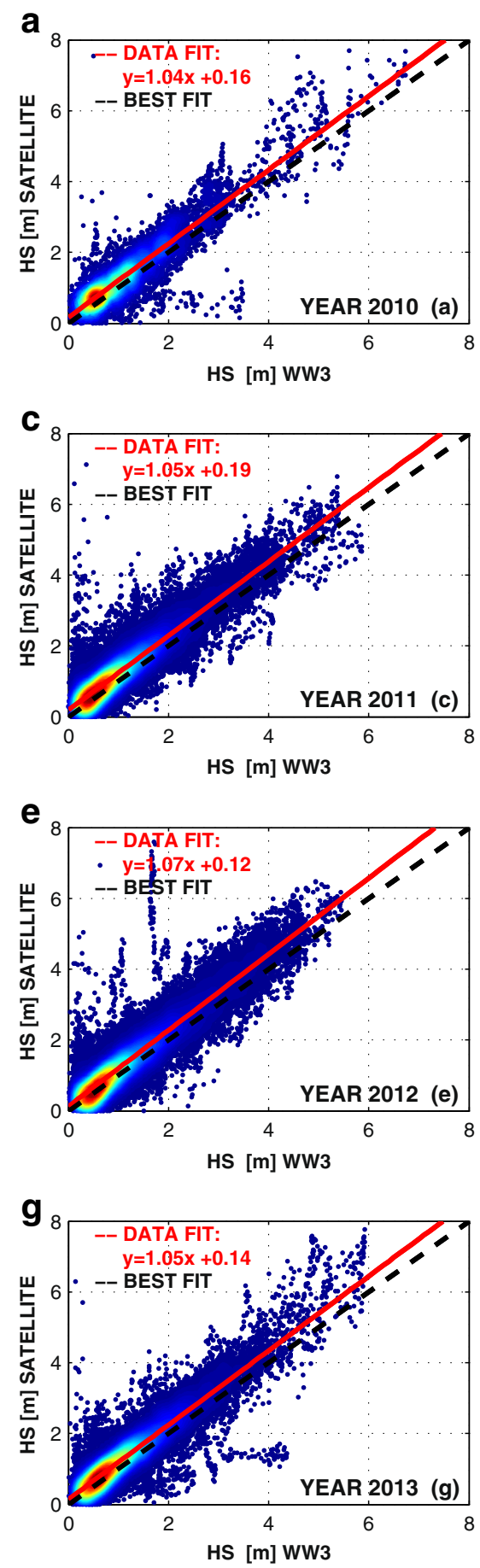

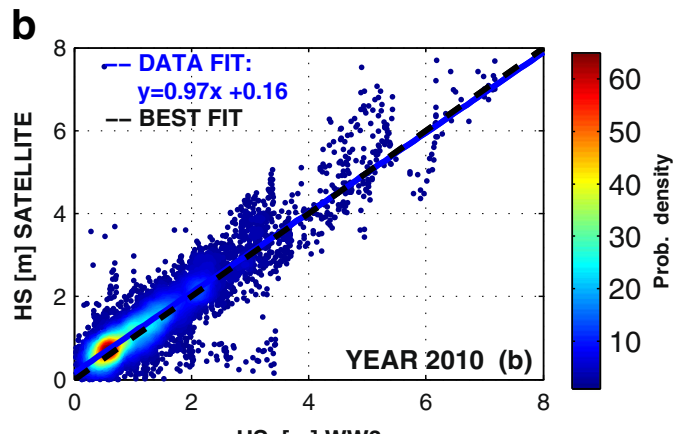

HS [m] WW3
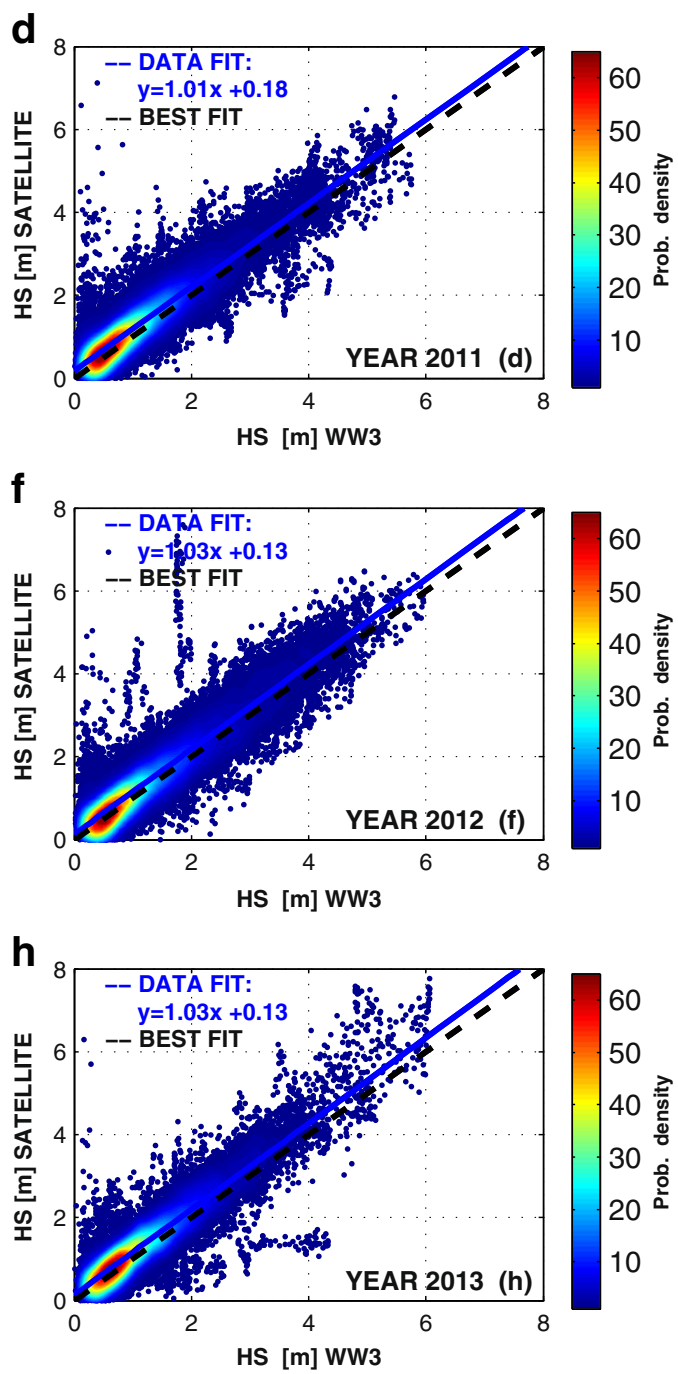
The fourth dataset is composed of vertical profiles of temperature and salinity measured by ARGO profiling floats integrated by the CMEMS In Situ Thematic Assembly Group (CMEMS INSITU-TAC), quality checked, and made available through the CMEMS catalogue.

\section{Results and discussion}

The ability of the models to represent the observations was evaluated by standard statistics such as: Bias, root mean square error (RMSE), normalized standard deviation (STDN), and correlation coefficient $(R)$ :

Bias $=\frac{1}{N} \sum_{i=1}^{N}\left(M_{i}-O_{i}\right)$

$R M S E=\sqrt{\frac{1}{N} \sum_{i=1}^{N}\left(M_{i}-O_{i}\right)^{2}}$

$S T D N=\frac{\sigma_{M}}{\sigma_{O}}=\sqrt{\frac{\sum_{i=1}^{N}\left(M_{i}-\bar{M}\right)^{2}}{\sum_{i=1}^{N}\left(O_{i}-\bar{O}\right)^{2}}}$

$R=\frac{\sum_{i=1}^{N}\left(M_{i}-\bar{M}\right)\left(O_{i}-\bar{O}\right)}{\sqrt{\frac{1}{N} \sum_{i=1}^{N}\left(M_{i}-\bar{M}\right)^{2}\left(O_{i}-\bar{O}\right)^{2}}}$

where $M$ represents the model fields, $O$ the observations, $N$ is the number of data, and the overbar indicates the time mean value over the whole period.

Table 3 Statistics evaluated by comparing satellite significant wave height $(H S)$ with uncoupled model results (EXP1) for years 2010 to 2013

\begin{tabular}{lrrrr}
\hline $\begin{array}{l}\text { Uncoupled } \\
\text { EXP1 HS [m] }\end{array}$ & Year 2010 & Year2011 & Year 2012 & Year 2013 \\
\hline Mean & & & & \\
CI & 1.203 & 1.001 & 1.119 & 1.119 \\
& +0.015 & +0.004 & +0.005 & +0.006 \\
Bias & -0.014 & -0.004 & -0.005 & -0.005 \\
CI & -0.213 & -0.236 & -0.208 & -0.195 \\
& +0.007 & +0.002 & +0.002 & +0.002 \\
RMSE & -0.007 & -0.002 & -0.002 & -0.003 \\
CI & 0.479 & 0.417 & 0.429 & 0.439 \\
& +0.015 & +0.005 & +0.007 & +0.018 \\
STDN & -0.014 & -0.004 & -0.07 & -0.015 \\
$R$ & 0.870 & 0.868 & 0.861 & 0.872 \\
& 0.906 & 0.909 & 0.925 & 0.916 \\
\hline
\end{tabular}

In order to compare statistics for different experiments, bootstrap $95 \%$ confidence intervals $(C I)$ were evaluated for the Mean, Bias, and RMSE metrics, being this approach applicable to any sample distribution.

This section is organized into three parts. The first describes the wave model comparison with buoys and altimeter data, highlighting the impact of the coupled system on waves. The second part shows the circulation model comparison with buoys, satellite, and ARGO measurements in order to assess the model performance in both uncoupled and coupled modes. The third one presents the effects of coupling on both waves and currents considering a short time scale analysis.

\subsection{Impact of the coupled system on waves}

Results of WW3 uncoupled (EXP1) and coupled (EXP3) experiments are compared to buoy measurements by daily averaged wave fields for the entire experimental period (2009-2013).

Figure $4 \mathrm{a}-\mathrm{f}$ shows scatter plots of buoy measurements versus the uncoupled (left) and coupled (right) numerical significant wave height (Fig. 4a, b), mean period (Fig. 4c, d), and peak period (Fig. 4e, f). The regression lines of the data from the buoys versus uncoupled and coupled model results (dashed red and blue lines, respectively) are also plotted in order to represent the distance from the best-fit (1:1) line (dashed black line). Different colors and markers correspond to different buoy networks.

Table 4 Statistics evaluated by comparing satellite significant wave height $(H S)$ with coupled model results (EXP3) for years 2010 to 2013 and coupled model results without Tolman (2002) wind correction (EXP4) for year 2010

\begin{tabular}{lrrrrr}
\hline Coupled & EXP3 & & & & \multirow{2}{*}{ EXP4 } \\
\cline { 2 - 5 } HS $[\mathrm{m}]$ & Year2010 & Year2011 & Year2012 & Year2013 & $\begin{array}{l}\text { Year } \\
2010\end{array}$ \\
& & & & & \\
\hline Mean & 1.304 & 1.047 & 1.166 & 1.143 & 1.271 \\
CI & +0.015 & +0.004 & +0.005 & +0.006 & +0.016 \\
& -0.016 & -0.004 & -0.005 & -0.006 & -0.016 \\
Bias & -0.112 & -0.190 & -0.162 & -0.170 & -0.253 \\
CI & +0.007 & +0.002 & +0.002 & +0.002 & +0.007 \\
& -0.007 & -0.002 & -0.002 & -0.003 & -0.007 \\
RMSE & 0.439 & 0.390 & 0.405 & 0.389 & 0.454 \\
CI & +0.018 & +0.004 & +0.009 & +0.004 & +0.014 \\
& -0.015 & -0.004 & -0.007 & -0.005 & -0.013 \\
STDN & 0.941 & 0.901 & 0.902 & 0.888 & 0.856 \\
$R$ & 0.908 & 0.91 & 0.925 & 0.918 & 0.934 \\
\hline
\end{tabular}



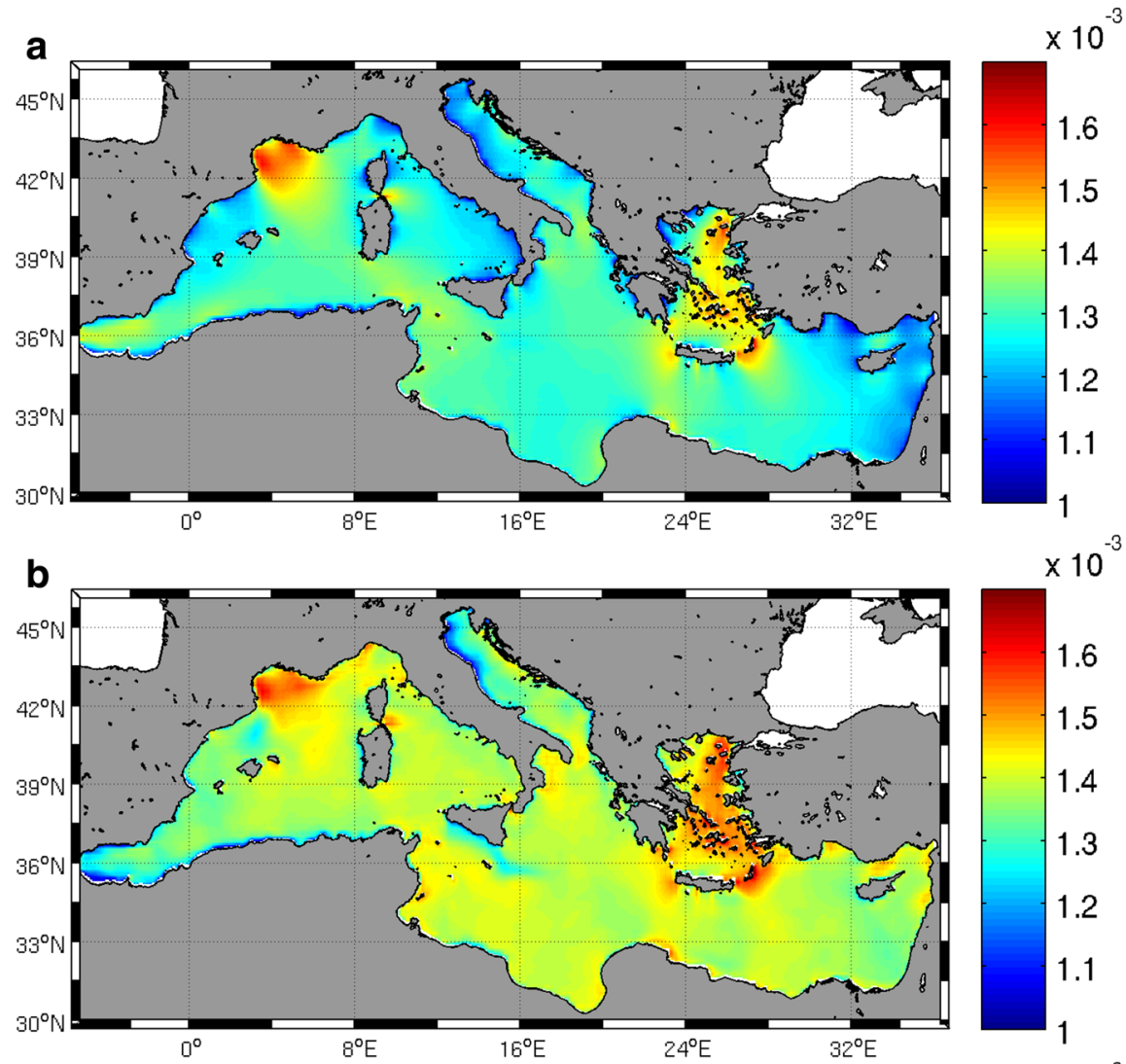

c

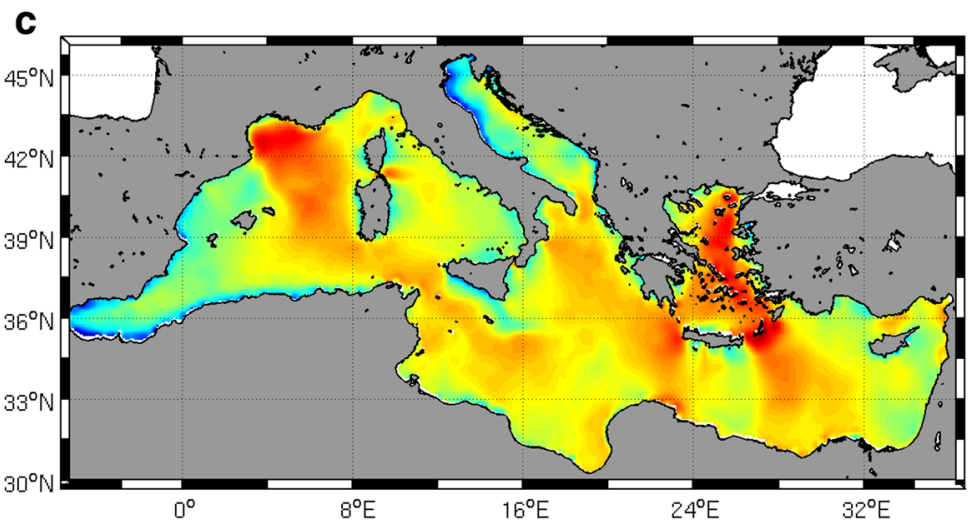

$\times 10^{-3}$

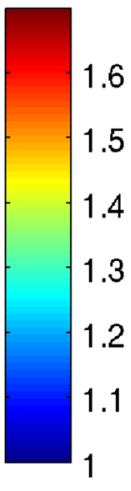

Diff (\%)
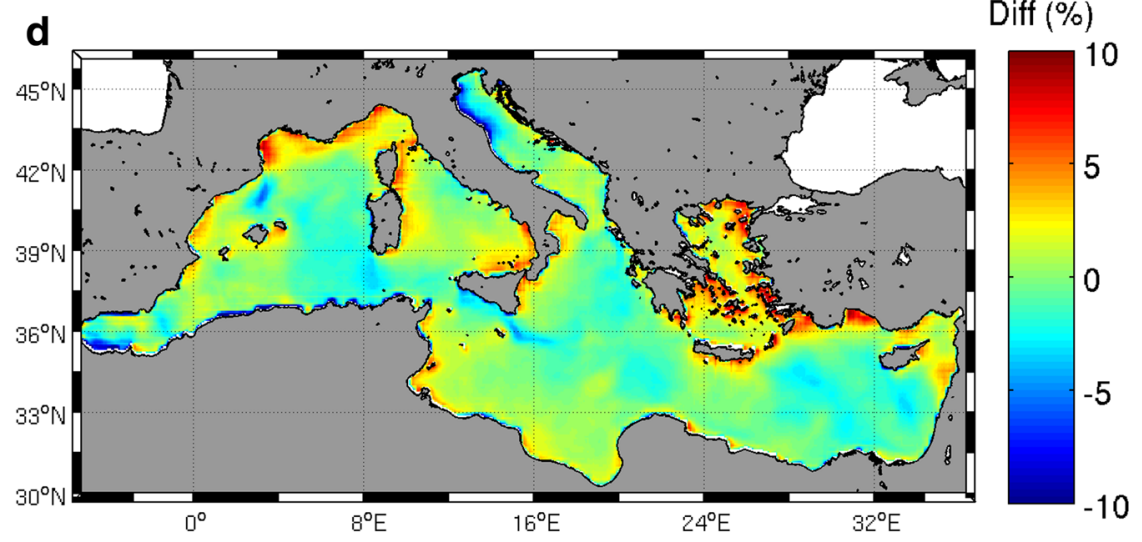

Fig. 8 Maps of drag coefficient averaged over the entire time period (2009-2013). a Neutral drag coefficient evaluated by WW3. b Turbulent drag coefficient evaluated by NEMO in coupled mode EXP3.

c Hellerman and Rosenstein (1983) turbulent drag coefficient in uncoupled NEMO EXP2. d Percentage difference between $\mathbf{b}$ and $\mathbf{c}$ 
Table 5 Statistics evaluated by comparing current amplitude measurements from buoy and model results in the uncoupled (EXP2) and coupled (EXP3) circulation model

\begin{tabular}{lll}
\hline Metric & $\begin{array}{l}\text { Surface currents } \\
\text { EXP2 }\end{array}$ & \multicolumn{1}{l}{$\begin{array}{l}\text { Surface currents } \\
\text { EXP3 }\end{array}$} \\
\hline Mean $[\mathrm{m} / \mathrm{s}]$ & $0.130 \pm 0.002$ & $0.133 \pm 0.002$ \\
$\operatorname{Bias}[\mathrm{m} / \mathrm{s}]$ & $-0.046 \pm 0.003$ & $-0.042 \pm 0.003$ \\
$\operatorname{RMSE}[\mathrm{m} / \mathrm{s}]$ & $0.160 \pm 0.003$ & $0.156 \pm 0.003$ \\
$\operatorname{STDN}$ & 0.87 & 0.88
\end{tabular}

The comparison of significant wave heights (Fig. 4a, b) shows that there is a relatively good agreement between measurements and the model output. In particular, the coupled model significant wave heights (Fig. 4a) correlate better with in situ observations than the uncoupled model estimates (Fig. 4b). In general, the model results underestimate the data from the buoys, particularly the largest wave heights, and similar outcomes have already been highlighted by Ardhuin et al. (2007) and Korres et al. (2011). In the period considered, the maximum daily average wave height was always lower than $6 \mathrm{~m}$, and $95 \%$ of wave heights came between 0.2 and $2 \mathrm{~m}$ for both measured and modelled data, with an average value of $0.8 \mathrm{~m}$ for measurements and $0.7 \mathrm{~m}$ for model results. These results are in agreement with other works carried out in the Mediterranean Sea for different periods and using different wave models by Cavaleri and Bertotti (2003) and Korres et al. (2011).

The comparison of mean and peak wave periods is represented in Fig. 4c, d and e, f, respectively, showing a
Table 6 Bias, RMSE, and confidence interval $(C I)$ values evaluated by comparing zonal surface velocities at coastal buoys listed in Table 9 (Appendix 1) for uncoupled (EXP2) and coupled (EXP3) model systems

\begin{tabular}{|c|c|c|c|c|c|c|}
\hline \multirow[t]{2}{*}{ Buoy no. } & \multicolumn{2}{|c|}{ Mean $[\mathrm{m} / \mathrm{s}]$} & \multicolumn{2}{|c|}{ Bias $[\mathrm{m} / \mathrm{s}]$} & \multicolumn{2}{|c|}{$R M S E[\mathrm{~m} / \mathrm{s}]$} \\
\hline & EXP2 & EXP3 & EXP2 & EXP3 & EXP2 & EXP3 \\
\hline \multicolumn{7}{|c|}{ Zonal velocity } \\
\hline 2 & 0.017 & 0.020 & -0.135 & -0.132 & 0.294 & 0.293 \\
\hline \multirow[t]{2}{*}{$C I$} & +0.010 & +0.010 & +0.014 & +0.014 & +0.009 & +0.010 \\
\hline & -0.011 & -0.010 & -0.014 & -0.013 & -0.010 & -0.010 \\
\hline 3 & -0.043 & -0.034 & -0.095 & -0.086 & 0.228 & 0.224 \\
\hline \multirow[t]{2}{*}{$C I$} & +0.004 & +0.005 & +0.010 & +0.010 & +0.012 & +0.010 \\
\hline & -0.005 & -0.005 & -0.010 & -0.010 & -0.012 & -0.011 \\
\hline 4 & 0.034 & -0.051 & 0.006 & 0.023 & 0.126 & 0.126 \\
\hline \multirow[t]{2}{*}{$C I$} & +0.004 & +0.004 & +0.006 & +0.006 & +0.005 & +0.004 \\
\hline & -0.003 & -0.04 & -0.006 & -0.005 & -0.005 & -0.004 \\
\hline 6 & 0.013 & 0.017 & 0.059 & 0.064 & 0.124 & 0.133 \\
\hline \multirow[t]{2}{*}{$C I$} & +0.003 & +0.003 & +0.006 & +0.006 & +0.005 & +0.005 \\
\hline & -0.003 & -0.003 & -0.005 & -0.005 & -0.005 & -0.05 \\
\hline 7 & 0.09 & 0.00 & 0.020 & 0.011 & 0.091 & 0.086 \\
\hline \multirow[t]{2}{*}{$C I$} & +0.003 & +0.003 & +0.004 & +0.004 & +0.003 & +0.003 \\
\hline & -0.003 & -0.003 & -0.004 & -0.004 & -0.003 & -0.003 \\
\hline 21 & 0.001 & -0.017 & 0.043 & 0.026 & 0.106 & 0.096 \\
\hline \multirow[t]{2}{*}{$C I$} & +0.010 & +0.009 & +0.016 & +0.015 & +0.012 & +0.012 \\
\hline & -0.011 & -0.009 & -0.015 & -0.015 & -0.012 & -0.012 \\
\hline 22 & -0.055 & -0.054 & 0.005 & 0.004 & 0.120 & 0.117 \\
\hline \multirow[t]{2}{*}{$C I$} & +0.004 & +0.004 & +0.007 & +0.007 & +0.006 & +0.007 \\
\hline & -0.005 & -0.004 & -0.007 & -0.007 & -0.006 & -0.006 \\
\hline 25 & -0.045 & -0.038 & 0.017 & 0.024 & 0.197 & 0.203 \\
\hline \multirow[t]{2}{*}{$C I$} & +0.0052 & +0.005 & +0.011 & +0.012 & +0.010 & +0.011 \\
\hline & -0.0052 & -0.005 & -0.011 & -0.012 & -0.011 & -0.011 \\
\hline 28 & -0.019 & -0.012 & -0.002 & 0.004 & 0.170 & 0.163 \\
\hline \multirow[t]{2}{*}{$C I$} & +0.005 & +0.005 & +0.010 & +0.010 & +0.011 & +0.011 \\
\hline & -0.005 & -0.005 & -0.010 & -0.010 & -0.010 & -0.011 \\
\hline
\end{tabular}

All the metrics are evaluated in $\mathrm{m} / \mathrm{s}$ 
Table 7 Bias, RMSE, and confidence interval $(C I)$ values evaluated by comparing meridional surface velocities at coastal buoys listed in Table 9 (Appendix 1) for uncoupled (EXP2) and coupled (EXP3) model systems

\begin{tabular}{|c|c|c|c|c|c|c|}
\hline \multirow[t]{2}{*}{ Buoy no. } & \multicolumn{2}{|c|}{ Mean $[\mathrm{m} / \mathrm{s}]$} & \multicolumn{2}{|c|}{ Bias $[\mathrm{m} / \mathrm{s}]$} & \multicolumn{2}{|c|}{$R M S E[\mathrm{~m} / \mathrm{s}]$} \\
\hline & EXP2 & EXP3 & EXP2 & EXP3 & EXP2 & EXP3 \\
\hline \multicolumn{7}{|c|}{ Meridional velocity } \\
\hline 2 & 0.020 & 0.043 & -0.014 & 0.009 & 0.143 & 0.155 \\
\hline \multirow[t]{2}{*}{$C I$} & +0.005 & +0.005 & +0.007 & +0.008 & +0.005 & +0.006 \\
\hline & -0.005 & -0.005 & -0.007 & -0.007 & -0.006 & -0.006 \\
\hline 3 & 0.054 & 0.063 & -0.009 & 0.001 & 0.189 & 0.203 \\
\hline \multirow[t]{2}{*}{$C I$} & +0.006 & +0.005 & +0.009 & +0.009 & +0.007 & +0.007 \\
\hline & -0.005 & -0.005 & -0.009 & -0.009 & -0.007 & -0.007 \\
\hline 4 & 0.100 & 0.131 & -0.06 & 0.025 & 0.161 & 0.171 \\
\hline \multirow[t]{2}{*}{$C I$} & +0.006 & +0.007 & +0.008 & +0.008 & +0.006 & +0.008 \\
\hline & -0.006 & -0.007 & -0.007 & -0.008 & -0.006 & -0.007 \\
\hline 6 & -0.055 & -0.043 & 0.077 & 0.090 & 0.174 & 0.178 \\
\hline \multirow[t]{2}{*}{$C I$} & +0.006 & +0.006 & +0.007 & +0.008 & +0.006 & +0.005 \\
\hline & -0.006 & -0.006 & -0.008 & -0.008 & -0.005 & -0.005 \\
\hline 7 & 0.018 & 0.012 & 0.026 & 0.020 & 0.095 & 0.085 \\
\hline \multirow[t]{2}{*}{$C I$} & +0.004 & +0.003 & +0.004 & +0.004 & +0.004 & +0.003 \\
\hline & -0.004 & -0.003 & -0.004 & -0.004 & -0.003 & -0.003 \\
\hline 21 & -0.023 & -0.025 & -0.023 & -0.025 & 0.099 & 0.096 \\
\hline \multirow[t]{2}{*}{$C I$} & +0.009 & +0.008 & +0.015 & +0.015 & +0.012 & +0.012 \\
\hline & -0.009 & -0.009 & -0.015 & -0.015 & -0.012 & -0.012 \\
\hline 22 & -0.053 & -0.055 & 0.001 & 0.003 & 0.117 & 0.111 \\
\hline \multirow[t]{2}{*}{$C I$} & +0.004 & +0.005 & +0.007 & +0.007 & +0.006 & +0.006 \\
\hline & -0.005 & -0.005 & -0.007 & -0.007 & -0.006 & -0.006 \\
\hline 25 & 0.016 & 0.010 & 0.012 & 0.006 & 0.174 & 0.175 \\
\hline \multirow[t]{2}{*}{$C I$} & +0.004 & +0.004 & +0.011 & +0.011 & +0.009 & +0.010 \\
\hline & -0.004 & -0.004 & -0.010 & -0.010 & -0.011 & -0.010 \\
\hline 28 & -0.007 & -0.010 & 0.017 & 0.014 & 0.158 & 0.158 \\
\hline \multirow[t]{2}{*}{$C I$} & +0.004 & +0.004 & +0.010 & +0.010 & +0.011 & +0.010 \\
\hline & -0.004 & -0.004 & -0.009 & -0.010 & -0.011 & -0.010 \\
\hline
\end{tabular}

All the metrics are evaluated in $\mathrm{m} / \mathrm{s}$

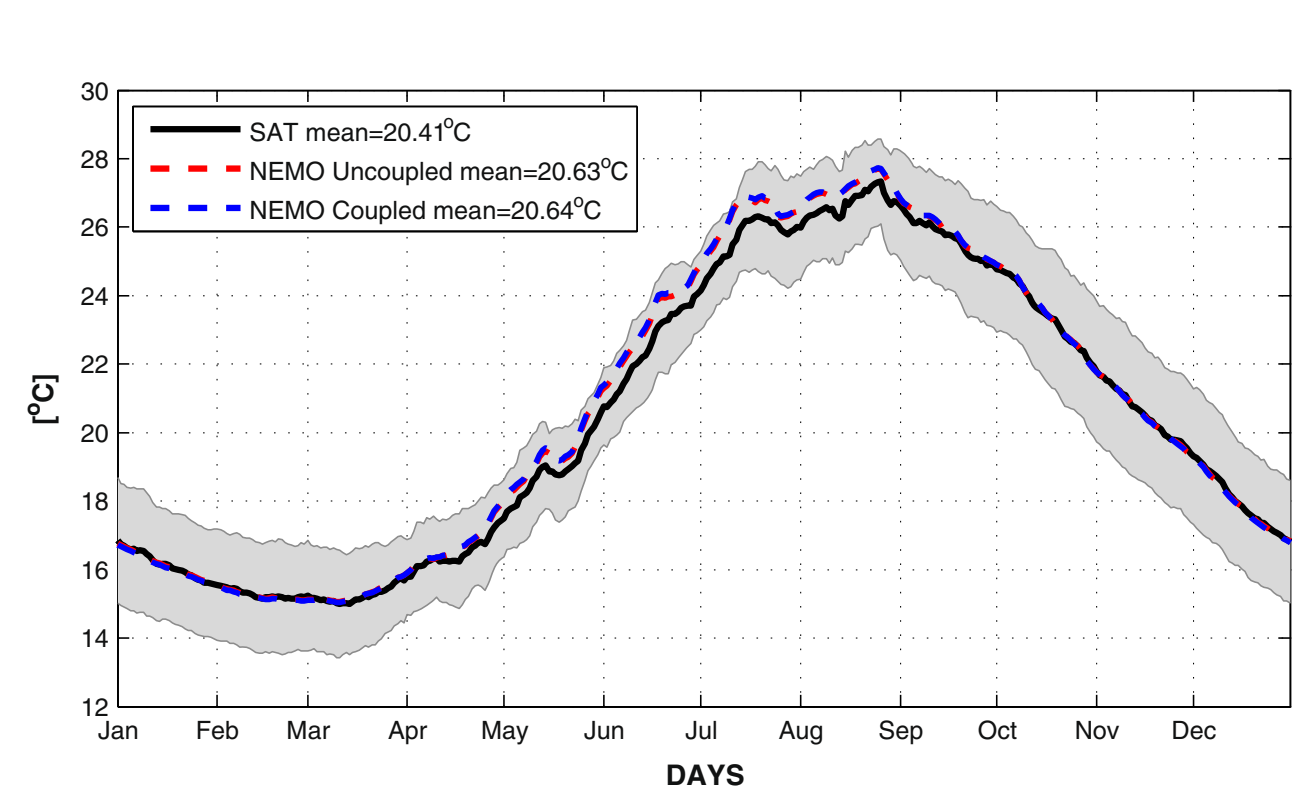

Fig. 9 Time series of climatological sea surface temperature (SST). Black line: satellite retrieved SST; dashed red line: NEMO uncoupled results (EXP2); dashed blue line: NEMO coupled (EXP3); shaded grey area: standard deviation of satellite data. The figure also lists values of mean SST 
Table 8 Statistics evaluated by comparing temperature and salinity vertical profile measurements and model results from uncoupled (EXP2) and coupled (EXP3) circulation models

\begin{tabular}{lllll}
\hline Metric & $\begin{array}{l}\text { Temperature } \\
\text { EXP2 }\left[{ }^{\circ} \mathrm{C}\right]\end{array}$ & $\begin{array}{l}\text { Temperature } \\
\text { EXP3 }\left[{ }^{\circ} \mathrm{C}\right]\end{array}$ & $\begin{array}{l}\text { Salinity } \\
\text { EXP2 [PSU] }\end{array}$ & $\begin{array}{l}\text { Salinity } \\
\text { EXP3 [PSU] }\end{array}$ \\
\hline Mean & 15.872 & 15.873 & 38.423 & 38.436 \\
$C I$ & +0.576 & +0.568 & +0.068 & +0.066 \\
& -0.550 & -0.505 & -0.062 & -0.064 \\
Bias & -0.051 & -0.051 & -0.149 & -0.136 \\
$C I$ & +0.013 & +0.017 & +0.018 & +0.017 \\
& -0.012 & -0.016 & -0.019 & -0.018 \\
RMSE & 0.069 & 0.079 & 0.165 & 0.152 \\
$C I$ & +0.010 & +0.014 & +0.016 & +0.013 \\
& -0.011 & -0.016 & -0.016 & -0.017 \\
$R$ & 1 & 1 & 0.988 & 0.992 \\
\hline
\end{tabular}

larger scatter with respect to the significant wave height data. Coupled model values correlate slightly more with observations than the uncoupled model. As already found by Korres et al. (2011) for uncoupled model simulations, the predicted mean period is lower than the measured one and presents a lower performance compared to the significant wave height. Mean period values are included between 2 and $10 \mathrm{~s}$ with an average value of $4.1 \mathrm{~s}$ for the model and $4.3 \mathrm{~s}$ for the measurements. Peak period values range between 2 and $12 \mathrm{~s}$ and the simulated values, characterized by an average value of $5 \mathrm{~s}$, underestimate the measured average value of $5.5 \mathrm{~s}$.
Table 2 summarizes the main statistics (Mean, Bias, RMSE, and their bootstrap $95 \% C I, S T D N$, and $R$ ) of significant wave height (HS), mean period (TM), and peak period (TP) for the buoy measurements. In all cases, the coupled model reproduces observations better than the uncoupled model. The coupled model significant wave height and mean period biases decrease by about $20 \%$ with respect to the uncoupled model, while the analysis of the $C I$ shows that the peak period results to be not affected by the coupling. Considering the model significant wave heights, these are characterized by lower standard deviation than the observations $(S T D N<1)$ and a high correlation (95\%). Both mean and peak model
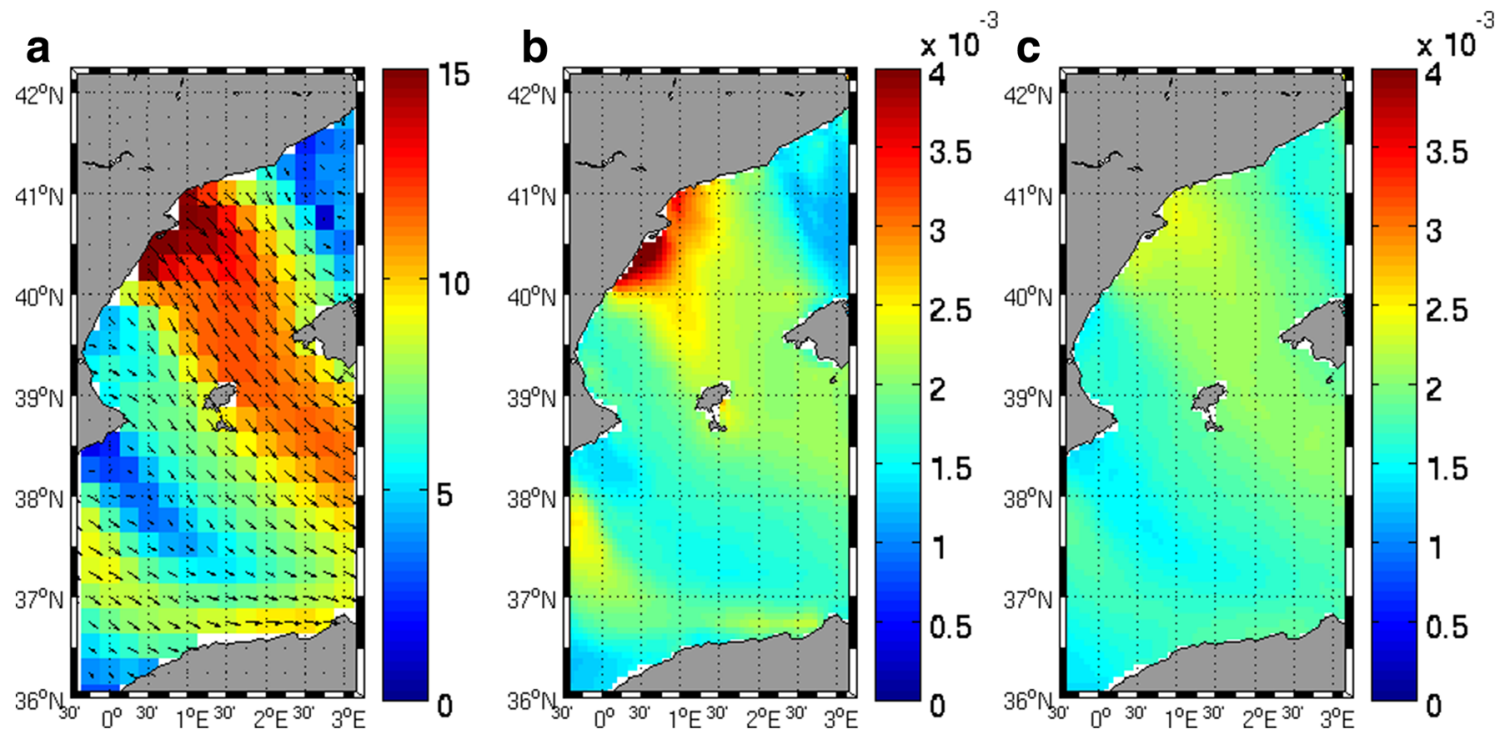

Fig. 10 Daily averaged maps of the Balearic Sea on the $26^{\text {th }}$ December 2010 for a wind speed at $10 \mathrm{~m}[\mathrm{~m} / \mathrm{s}]$, b turbulent drag coefficient in coupled system (EXP3), and $\mathbf{c}$ turbulent drag coefficient in uncoupled system (EXP2) 

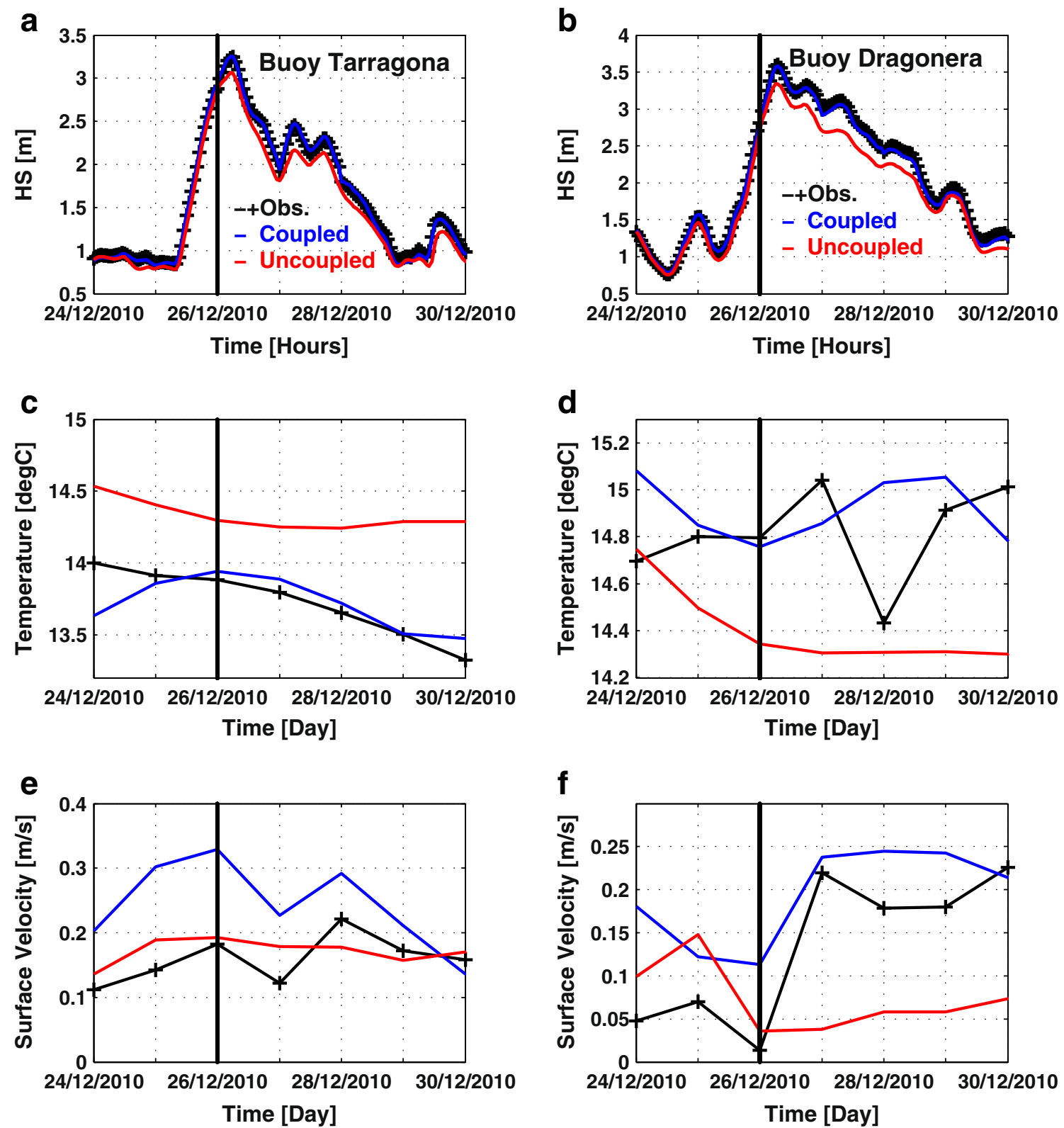

Fig. 11 Time series at Tarragona $(\mathbf{a}, \mathbf{c}, \mathbf{e})$ and Dragonera $(\mathbf{b}, \mathbf{d}, \mathbf{f})$ coastal buoys for the period 26-30 December 2010 for hourly significant wave height $[\mathrm{m}](\mathbf{a}, \mathbf{b})$, daily surface temperature $\left[{ }^{\circ} \mathrm{C}\right](\mathbf{c}, \mathbf{d})$, and daily surface

periods are more dispersed than the measurements $(S T D N>1)$ with a correlation of about $75 \%$ for the mean period and $85 \%$ for the peak period.

In order to check the spatial pattern of the errors, Fig. 5 shows significant wave height RMSE (yellow to red triangles) and Bias (green to blue circles) of the coupled model results. Some regionalization of the errors is evident: the model

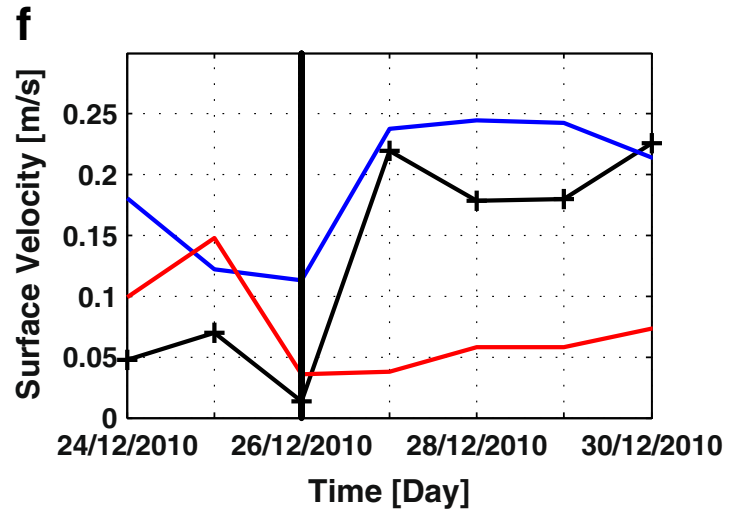

current velocity $[\mathrm{m} / \mathrm{s}](\mathbf{e}, \mathbf{f})$. Black lines represent measurements; blue lines correspond to coupled system results; red lines show uncoupled system results

performs better in the Aegean Sea, but not in the Western Ionian Sea. However, the Adriatic, Tyrrhenian, and Ligurian seas have small error values as well as on the Southern Spanish coast.

Daily averaged significant wave height time series of the Valencia buoy (Puertos del Estado network), where the statistics are more robust due to the long measurement time series, 
are shown in Fig. 6a-e for the years 2009 to 2013 (black line) with corresponding uncoupled (red dashed line) and coupled (blue dashed line) model results. Both experiments correctly reproduce the significant wave height variability and on average underestimate measurements (negative Bias for all the years and experiments). Averaging over the entire simulated period, the coupled model system presents a lower Bias $(-11 \%)$ and $R M S E(-5 \%)$ compared to the uncoupled experiment.

Considering that the comparison with the coastal buoy data could be affected by the coastline and shallow water bathymetry representation, by the relatively coarse resolution models, the significant wave heights were also assessed by comparing them with Jason-2 observations (Fig. $7 \mathrm{a}-\mathrm{h}$ and Tables 3 and 4).

Figure $7 \mathrm{a}-\mathrm{h}$ shows how the model results fit the altimeter data from 2010 to 2013. For all the years, the coupled model performs better than the uncoupled WW3. The main statistics for EXP1 and EXP3 are listed in Tables 3 and 4, respectively, and show that the coupled model decreases the Bias by about $25 \%$.

The impact of wave-current interaction without considering wind speed correction was also evaluated by performing a 1-year (2010) integration of the system where the Tolman (2002) correction in Eq. 9 was not used (EXP4). Thus, only the exchange of currents and wind drag between NEMO to WW3 was kept. Model results were compared to satellite altimeter significant wave height and are summarized in Table 4 (last column) showing that this simple current-wave interaction coupling slightly improves the RMSE but worsens the Bias. This result is in agreement with previous studies by Galanis et al. (2012) probably due to the still coarse resolution of the models and the winds used in both studies. In a semienclosed basin like the Mediterranean Sea, where the windsea strongly determines the shape of the wave spectrum, better improvements in the wave field predictions could be achieved by using higher resolution winds. This is evidenced by Ardhuin et al. (2007) who demonstrate that different forcing winds produce larger wave differences than using different wave models.

\subsection{Impact of the coupled system on the hydrodynamic fields}

The effects of waves on the hydrodynamics are only due to the usage of the turbulent wind drag coefficient shown in Eq. 23. Figure $8 \mathrm{a}, \mathrm{b}$ shows maps of the neutral drag coefficient estimated by WW3 and the turbulent drag coefficient estimated by NEMO (in EXP3), respectively, following the methodology explained in Appendix 3. Figure 8c shows the turbulent surface drag coefficient as parameterized by the uncoupled
NEMO model using the Hellerman and Rosenstein (1983) formulation (in EXP2). The two turbulent drag coefficient formulations (Fig. 8b, c) show a similar pattern. The differences between the coupled and uncoupled drag coefficient, shown in Fig. $8 \mathrm{~d}$ as a percentage difference, are concentrated in the coastal areas especially of the Aegean and the LiguroProvençal basin. Overall, the changes are of the order of $10 \%$ and are mainly attributed to the changed $C d$ provided by the WW3 model. All the maps in Fig. 8 are evaluated as time averages over the entire 5 -year period.

In order to evaluate the impact of the coupled system on the circulation model, we compared model surface currents with coastal buoy measurements; the sea surface temperature was validated using satellite data, and vertical profiles of temperature and salinity were compared to ARGO floating measurements.

Table 5 summarizes the main statistics derived from the comparison of model results and buoy surface current amplitude, showing that a slight improvement is achieved when coupling with waves (lower Bias and RMSE): model predictions generally underestimate measurements and have lower standard deviations; however, the $C I$ show that the differences between the two systems are negligible (note that in this case the limits of the $C I$ correspond since these differ at the fourth decimal).

Tables 6 and 7 evaluate the Bias and RMSE of the single zonal and meridional components of the surface velocities, respectively, thus giving an estimate of the impact on current directions. Again, the improvements in the coupled model system are too small to be significant and metrics $C I$ are in some cases larger than the improvements.

Figure 9 shows the 5-year mean SST from EXP2 and EXP3 compared with satellite derived SST. The model overestimates satellite $S S T$ in the spring and summer seasons showing a positive Bias of about $0.5^{\circ} \mathrm{C}$. However, it is still confined within one standard deviation and there is no substantial difference between the results of the two experiments.

Table 8 summarizes the Mean, Bias, RMSE, their confidence intervals $(C I)$, and the correlation coefficient $R$ metrics for both uncoupled (EXP2) and coupled (EXP3) model systems for temperature and salinity profiles compared with ARGO and integrated along the first $500 \mathrm{~m}$. As for the $S S T$, there are no significant differences between the two experiments.

We conclude that the effects of the different waveinduced turbulent wind drag coefficients have a small, if nonexistent, impact on the quality of the simulated current, temperature, and salinity fields when considering space or time averaged fields. Possible impacts on restricted area at short time scale are presented in the following section. 


\subsection{Wave-current coupling at short time scale}

The performance of the system was evaluated considering an event of particularly high wind speed and assessing the role of the wave effects on coastal circulation and temperature as well as the effect that the circulation and temperature exert on the waves. The selected event, which is considered interesting in terms of both atmospheric conditions/extreme events and observational data availability, took place on the $26^{\text {th }}$ December 2010 in the Balearic Sea with maximum wind speed $\left(\mathrm{U}_{10}\right)$ higher that $20 \mathrm{~m} / \mathrm{s}$ close to the Spanish coastal area of Tarragona with a maximum daily average velocity of about $15 \mathrm{~m} / \mathrm{s}$ as represented in Fig. 10a. The turbulent drag coefficient evaluated in the selected area by the coupled and uncoupled systems for the considered day are represented in Fig. 10b, c showing that when the coupling is activated, the drag coefficient has a spatial pattern similar to the wind field with higher values in the area affected by the storm.

The modelled significant wave height, surface temperature, and currents have been compared to in situ observations at the Tarragona and Dragonera buoys (buoy nos. 6 and 4 in Table 9 and Fig. 3) for 1 week: from the $24^{\text {th }}$ December 2010 ( 2 days before the selected event) to the $30^{\text {th }}$ December 2010 ( 4 days after the event).

Hourly time series of significant wave height are presented in Fig. 11a, b for the Tarragona and the Dragonera buoy, respectively, showing an improved skill of the coupled system resulting intensified by the interaction with the hydrodynamic fields with respect to the uncoupled one.

The comparison of the modelled surface temperature against daily observations at the Tarragona buoy is presented in Fig. 11c where the coupled model shows a good agreement with the measurements with respect to the uncoupled one, which overestimates the buoy surface temperature. Figure 11d illustrates the surface temperature at the Dragonera buoy showing that the uncoupled model underestimates the observations, while the coupled one provides more reliable predictions of the measurements especially in correspondence of the storm event.

Figure 11e, f shows that the coupled model overestimates the measured surface currents at the Tarragona and Dragonera buoys, but it better represents the evolution of the measured velocity after the extreme event with respect to the uncoupled model, which is less affected by the increased wind speed.

The short time scale analysis for the selected event demonstrates that both wave and hydrodynamic fields are affected by the coupling, resulting in an enhanced skill, particularly of the modelled significant wave heights and, to a lesser extent, of the surface temperature and current fields.

\section{Conclusions}

A coupled wave-current numerical model system was developed and validated against observations for a 5 -year period between 2009 and 2013. The coupled model was implemented in the Mediterranean Sea using NEMO and WW3 model codes. Fields were exchanged hourly between the two components while atmospheric forcing fields from ECMWF were interpolated to the single model time steps.

The coupling consists of feeding the wave model with sea surface temperature and surface currents computed by the hydrodynamic model and returning a neutral wind drag coefficient to the latter, which then computes a turbulent wind drag coefficient used in the momentum surface boundary condition.

One major conclusion drawn from the various results presented in the work is that the wave model is impacted by this kind of wind wave-hydrodynamic model coupling, while the hydrodynamics changes are negligible at large space and time scales becoming more evident when considering the coupling impacts during storm events.

Both the uncoupled and coupled wave models perform well in reproducing in situ as well as satellite measured wave parameters, and the coupled system improves the significant wave height simulation values with respect to the uncoupled system. The results also highlight that the enhanced performance of the coupled model is mainly achieved by better representing effect of air-sea temperature differences impacting the wave growth, while surface currents lead to only a minor improvement. This might be due to the low resolution of the hydrodynamic and wave models and in particular to the scarce resolution of the coastal areas geometry and bathymetry.

The wave-induced turbulent wind drag correction and the traditional Hellerman and Rosenstein (1983) formulations differ significantly only in the coastal areas and even there only by $10-20 \%$. The impact of the coupling on the simulated hydrodynamic fields is thus much lower, and most of the time is negligible. Evidence of the effect of wave dependent surface stress on the computation of coastal currents and temperature is shown on a short time scale analysis, while, on the typical time scale of ocean circulation, the main effect is expected because of a wave-dependent ocean mixing, which is not included in this study.

We probably need to wait for a stronger coupling between waves and currents before an improvement in the hydrodynamics will be evident. Future work in fact will consider the wave dissipated energy (as provided by the wave model) in the vertical mixing of the water column and will add the Stokes drift velocity in the momentum and tracer equations. 
The present work suggests that a two-way coupled model could improve the prediction of wave characteristics, in particular the significant wave height, for both open ocean and coastal areas.

Acknowledgements This work was supported by the CMEMS Med-MFC (Copernicus Marine Environment Monitoring ServiceMediterranean Marine Forecasting Centre), Mercator Ocean Service Contract and RITMARE Flagship Project (National Research Programmes), Italian Ministry of University and Research contract.

We would like to thank Dr. Enrique Alvarez-Fanijul and Dr. Marta de Alfonso (Puertos de l'Estado, ES), Dr. Joaquin Tintoré (CSIC, ES), Mr. Leonidas Perivoliotis (HCMR, GR), and Dr. Gabriele Nardone (ISPRA, IT).

\section{Appendix 1}

The list of coastal moored buoys is presented in Table 9, including the corresponding number, name, location, network, and distinguishing between wave measuring (W) and current measuring (UV) buoys.

Table 9 List of wave (W) and current (UV) buoy locations illustrated in Fig. 3 and data providers

\begin{tabular}{|c|c|c|c|c|c|}
\hline $\begin{array}{l}\text { Buoy } \\
\text { no. }\end{array}$ & Buoy name & Lat & Lon & Network & $\begin{array}{l}\text { W/ } \\
\text { UV }\end{array}$ \\
\hline 1 & Cabo Begur & $\mathrm{N} 41^{\circ} 54^{\prime} 53^{\prime \prime}$ & $\mathrm{E} 03^{\circ} 38^{\prime} 42^{\prime \prime}$ & PUERTOS & W,UV \\
\hline 2 & Cabo de Gata & $\mathrm{N} 36^{\circ} 34^{\prime} 12^{\prime \prime}$ & $\mathrm{W} 02^{\circ} 20^{\prime} 23^{\prime \prime}$ & PUERTOS & W,UV \\
\hline 3 & Cabo de Palos & N $37^{\circ} 39^{\prime} 04^{\prime \prime}$ & $\mathrm{W} 00^{\circ} 19^{\prime} 28^{\prime \prime}$ & PUERTOS & W,UV \\
\hline 4 & Dragonera & N $39^{\circ} 33^{\prime} 17^{\prime \prime}$ & E $02^{\circ} 06^{\prime} 06^{\prime \prime}$ & PUERTOS & W,UV \\
\hline 5 & Mahon & N $39^{\circ} 43^{\prime} 47^{\prime \prime}$ & E $04^{\circ} 25^{\prime} 11^{\prime \prime}$ & PUERTOS & W,UV \\
\hline 6 & Tarragona & $\mathrm{N} 40^{\circ} 41^{\prime} 02^{\prime \prime}$ & $\mathrm{E} 01^{\circ} 28^{\prime} 05^{\prime \prime}$ & PUERTOS & W,UV \\
\hline 7 & Valencia & N $39^{\circ} 30^{\prime} 57^{\prime \prime}$ & E $00^{\circ} 12^{\prime} 16^{\prime \prime}$ & PUERTOS & W,UV \\
\hline 8 & Ancona & $\mathrm{N} 43^{\circ} 49^{\prime} 30^{\prime \prime}$ & E $13^{\circ} 43^{\prime} 09^{\prime \prime}$ & ISPRA & W \\
\hline 9 & Cagliari & $\mathrm{N} 39^{\circ} 06^{\prime} 54^{\prime \prime}$ & E $09^{\circ} 24^{\prime} 17^{\prime \prime}$ & ISPRA & W \\
\hline 10 & Catania & N $37^{\circ} 26^{\prime} 23^{\prime \prime}$ & E $15^{\circ} 08^{\prime} 48^{\prime \prime}$ & ISPRA & W \\
\hline 11 & Siniscola & $\mathrm{N} 40^{\circ} 37^{\prime} 00^{\prime \prime}$ & $\mathrm{E} 09^{\circ} 53^{\prime} 30^{\prime \prime}$ & ISPRA & W \\
\hline 12 & Cetraro & N $39^{\circ} 27^{\prime} 02^{\prime \prime}$ & E $15^{\circ} 55^{\prime} 00^{\prime \prime}$ & ISPRA & $\mathrm{W}$ \\
\hline 13 & Civitavecchia & $\mathrm{N} 42^{\circ} 14^{\prime} 40^{\prime \prime}$ & E $11^{\circ} 33^{\prime} 14^{\prime \prime}$ & ISPRA & W \\
\hline 14 & Crotone & $\mathrm{N} 39^{\circ} 01^{\prime} 24^{\prime \prime}$ & E $17^{\circ} 13^{\prime} 11^{\prime \prime}$ & ISPRA & $\mathrm{W}$ \\
\hline 15 & La Spezia & $\mathrm{N} 43^{\circ} 55^{\prime} 45^{\prime \prime}$ & Е $09^{\circ} 49^{\prime} 40^{\prime \prime}$ & ISPRA & $\mathrm{W}$ \\
\hline 16 & Mazara & $\mathrm{N} 37^{\circ} 31^{\prime} 05^{\prime \prime}$ & E $12^{\circ} 31^{\prime} 59^{\prime \prime}$ & ISPRA & W \\
\hline 17 & Ortona & $\mathrm{N} 42^{\circ} 24^{\prime} 24^{\prime \prime}$ & E $14^{\circ} 32^{\prime} 09^{\prime \prime}$ & ISPRA & W \\
\hline 18 & Palermo & $\mathrm{N} 38^{\circ} 15^{\prime} 29^{\prime \prime}$ & E $13^{\circ} 19^{\prime} 59^{\prime \prime}$ & ISPRA & W \\
\hline 19 & Ponza & $\mathrm{N} 40^{\circ} 52^{\prime} 00^{\prime \prime}$ & E $12^{\circ} 56^{\prime} 59^{\prime \prime}$ & ISPRA & W \\
\hline 20 & Venezia & $\mathrm{N} 45^{\circ} 20^{\prime} 00^{\prime \prime}$ & $\mathrm{E} 12^{\circ} 31^{\prime} 00^{\prime \prime}$ & ISPRA & $\mathrm{W}$ \\
\hline 21 & Zakynthos & $\mathrm{N} 37^{\circ} 56^{\prime} 48^{\prime \prime}$ & E $20^{\circ} 36^{\prime} 13^{\prime \prime}$ & HCMR & W,UV \\
\hline 22 & Santorini & $\mathrm{N} 36^{\circ} 15^{\prime} 43^{\prime \prime}$ & E $25^{\circ} 29^{\prime} 46^{\prime \prime}$ & HCMR & W,UV \\
\hline 23 & Mykonos & $\mathrm{N} 37^{\circ} 30^{\prime} 36^{\prime \prime}$ & E $25^{\circ} 27^{\prime} 29^{\prime \prime}$ & HCMR & W,UV \\
\hline 24 & Lesvos & N $39^{\circ} 09^{\prime} 28^{\prime \prime}$ & E $25^{\circ} 48^{\prime} 46^{\prime \prime}$ & HCMR & W,UV \\
\hline 25 & Athos & $\mathrm{N} 39^{\circ} 57^{\prime} 50^{\prime \prime}$ & E $24^{\circ} 43^{\prime} 12^{\prime \prime}$ & HCMR & W,UV \\
\hline 26 & Pylos & N $36^{\circ} 49^{\prime} 31^{\prime \prime}$ & E $21^{\circ} 35^{\prime} 45^{\prime \prime}$ & HCMR & W,UV \\
\hline 27 & E1-M3A & $\mathrm{N} 35^{\circ} 46^{\prime} 42^{\prime \prime}$ & E $24^{\circ} 55^{\prime} 12^{\prime \prime}$ & HCMR & W,UV \\
\hline 28 & Skyros & $\mathrm{N} 39^{\circ} 06^{\prime} 21^{\prime \prime}$ & E $24^{\circ} 27^{\prime} 34^{\prime \prime}$ & HCMR & W,UV \\
\hline 29 & Kalamata & N $36^{\circ} 58^{\prime} 19^{\prime \prime}$ & E $22^{\circ} 05^{\prime} 44^{\prime \prime}$ & HCMR & W,UV \\
\hline 30 & Saronikos & $\mathrm{N} 37^{\circ} 36^{\prime} 02^{\prime \prime}$ & E $23^{\circ} 33^{\prime} 49^{\prime \prime}$ & HCMR & W,UV \\
\hline 31 & Cabrera & $\mathrm{N} 39^{\circ} 13^{\prime} 28^{\prime \prime}$ & E $02^{\circ} 57^{\prime} 59^{\prime \prime}$ & CSIC & W,UV \\
\hline 32 & Enderrocat & $\mathrm{N} 39^{\circ} 29^{\prime} 49^{\prime \prime}$ & $\mathrm{E} 02^{\circ} 42^{\prime} 02^{\prime \prime}$ & CSIC & W,UV \\
\hline
\end{tabular}

\section{Appendix 2}

The CPP (C Pre-Processor) keys used in the numerical experiments, NEMO uncoupled and WW3-NEMO coupled model configurations, are listed in Table 10. The model configuration and corresponding namelist variables are also listed in Table 11.

Table 10 List of the NEMO model configuration CPP keys adopted

\begin{tabular}{ll}
\hline CPP key & Associated process \\
\hline key_dynspg_ts & Split-explicit free surface \\
key_mfs & MFS bulk formulation \\
key_obc & Lateral boundary condition with \\
& open boundaries parameters \\
key_zdfric & Richardson number-dependent \\
key_iomput & vertical diffusion \\
key_mpp_mpi & Outputs are selected in iodef.xml \\
\hline
\end{tabular}

Table 11 List of the NEMO model configuration setup

\begin{tabular}{|c|c|}
\hline Parameter & Value \\
\hline NEMO model version & 3.4 stable \\
\hline Horiz. resolution & $1 / 16^{\circ}$ \\
\hline Vertical discretization & $72 \mathrm{z}$ levels with partial cells $(\ln z p s=. t r u e)$. \\
\hline Time-step & $600 \mathrm{~s}$ \\
\hline Initial condition & $\begin{array}{l}\text { Restart from operational system Mef-MFC } \\
(2008-12-31)\end{array}$ \\
\hline Air-sea fluxes & MFS-Bulk formulae $\left(l n \_b l k \_m f s=. t r u e.\right)$ \\
\hline Neutral drag & NEMO uncoupled (ln_c $\bar{c} d g \bar{w}=$.false.) \\
\hline coefficient & NEMO coupled: read from file ( $\ln \_d g w=$.true. $)$ \\
\hline Runoff & $\begin{array}{l}\text { As a surface boundary condition for } \mathrm{S} \text { and } \mathrm{w} \\
\left(\ln \_r n f=. \text { true. }\right)\end{array}$ \\
\hline $\begin{array}{l}\text { Sea surface restoring } \\
\mathrm{T} / \mathrm{S}\end{array}$ & Yes $($ ln_ssr $=$. true. $)$ \\
\hline Solar radiation & 2-band penetration $\left(\ln \_q s r \_2 b d=\right.$.true. $)$ \\
\hline $\begin{array}{l}\text { Lateral momentum } \\
\text { B.C. }\end{array}$ & No-sleep $\left(r n \_s h l a t=2\right)$ \\
\hline \multirow[t]{2}{*}{ Open boundaries } & Climatological OBC data files \\
\hline & $\begin{array}{l}\text { Flather open boundary condition } \\
(\text { ln_obc_fla }=\text {.true. })\end{array}$ \\
\hline Bottom B.C & Non linear friction $\left(n n \_b f r=2\right)$ \\
\hline EOS & $\begin{array}{l}\text { UNESCO - Jackett and McDougall (1994) } \\
\left(n n \_ \text {eos }=0\right)\end{array}$ \\
\hline Tracer advection & Up-stream/MUSCL $($ ln traadv_muscl $=$. true. $)$ \\
\hline Horiz. diffusivity & $\begin{array}{l}\text { Bi-Laplacian Aht }=-6 . \overline{\mathrm{e}} 8 \mathrm{~m}^{4} \mathrm{~s}^{-1} \\
(\text { ln_traldf_bilap }=. \text { true. })\end{array}$ \\
\hline Horiz. viscosity & $\begin{array}{l}\text { Bi-Laplacian Ahm }=-1 \mathrm{e} .9 \mathrm{~m}^{4} \mathrm{~s}^{-1} \\
(\text { ln_dynldf_bilap }=. \text { true. })\end{array}$ \\
\hline Momentum advection & $\begin{array}{l}\text { Vector form (energy and enstrophy cons. scheme) } \\
(\text { ln_dynadv_vec }=. t r u e . \text { In_dynvor_een }=. t r u e .)\end{array}$ \\
\hline Back. vertical visc. & $\mathrm{Amv}=1.2 \mathrm{e}^{-} 5 \mathrm{~m}^{2} \mathrm{~s}^{-1}$ \\
\hline Back. vertical diff. & Avt $=1.2 \mathrm{e}-6 \mathrm{~m}^{2} \mathrm{~s}^{-1}$ \\
\hline Vertical scheme & Implicit (ln_zdfexp $=$.false. $)$ \\
\hline Vertical visc. scheme & Pacanowski \& Philander (key_zdfric) \\
\hline $\begin{array}{l}\text { Free-surface } \\
\quad \text { formulation }\end{array}$ & $\begin{array}{l}\text { Linear free surface (fixed volume: } k e y \_v v l \text { not } \\
\text { activated) }\end{array}$ \\
\hline & Split-explicit free surface $\left(k e y \_d y n s p g \_t s\right)$ \\
\hline Atmospheric pressure & Yes $($ ln_apr_dyn $=$.true. $)$ \\
\hline
\end{tabular}




\section{Appendix 3. Turbulent wind drag coefficient computation}

Here, we use the Large and Yeager (2004) and Large (2006) iterative algorithm to compute the air temperature and specific humidity at the wind height $\left(z_{u}\right)$ which is $10 \mathrm{~m}$ for our model fields, and then compute the turbulent drag coefficient at this height. The turbulent fields $\left(T^{*}, U^{*}, q^{*}\right)$ are computed using the neutral drag coefficient estimated by the wave model $\left(C_{D}=C_{D n}\right)$ as first guess:

$T^{*}=\frac{C h}{\sqrt{C_{D}}}\left(T_{z u}-S S T\right)$

$U^{*}=\sqrt{C_{D} \cdot|\Delta \boldsymbol{U}|}$

$q^{*}=\frac{C_{e}}{\sqrt{C_{D}}}\left(q_{z u}-q_{s a t}\right)$

where $T_{z u}$ and $q_{z u}$ are the air temperature and the specific humidity, respectively, at $10 \mathrm{~m}, q_{\text {sat }}$ is sea surface specific humidity, and $C e$ and $C h$ are the latent and sensible heat transfer coefficients, respectively.

The virtual potential temperature $T_{v}$ is computed as follows:

$T_{v}=T_{z u}\left(1+0.608 q_{z u}\right)$

where 0.608 is the ratio between dry air and water vapor molecular weights minus 1 .

The stability parameter is computed as the ratio between the 10-m height and the Monin-Obukov length $(L)$ as follows:

$\zeta_{u}=\frac{z_{u}}{L}=\frac{\kappa g z_{u}}{U^{* 2}}\left[\frac{T^{*}}{T_{v}}+\frac{q^{*}}{\left(q_{z u}+0.608^{-1}\right)}\right]$

In Eq. 20 the Monin-Obukov length $L$ was evaluated by approximating the virtual potential temperature flux according to Brodeau (2007).

The stability function $\psi_{m}\left(\zeta_{u}\right)$ is as follows:

$$
\begin{aligned}
\psi_{m}\left(\zeta_{u}\right)= & -5 \zeta_{u} \quad \text { stable } \zeta_{u}>0 \\
\psi_{m}\left(\zeta_{u}\right)= & 2 \ln \left(\frac{1+X}{2}\right)+\ln \left(\frac{1+X^{2}}{2}\right) \\
& -2 \tan ^{-1}(X)+\frac{\pi}{2} \quad \text { unstable } \zeta_{u} \leq 0
\end{aligned}
$$

where $X=\left(1-16 \zeta_{u}\right)^{1 / 4}$.

The final turbulent wind stress drag coefficient is then defined as follows:

$$
C_{D}=\frac{C_{D n}}{\left[1-\frac{\sqrt{C_{D n}} \psi_{m}\left(\zeta_{u}\right)}{\kappa}\right]^{2}}
$$

Open Access This article is distributed under the terms of the Creative Commons Attribution 4.0 International License (http:// creativecommons.org/licenses/by/4.0/), which permits unrestricted use, distribution, and reproduction in any medium, provided you give appropriate credit to the original author(s) and the source, provide a link to the Creative Commons license, and indicate if changes were made.

\section{References}

Alari V, Staneva J, Breivik Ø, Bidlot JR, Mogensen K, Janssen P (2016) Surface wave effects on water temperature in the Baltic Sea: simulations with the coupled NEMO-WAM model. Ocean Dyn 66(8): 917-930

Ardhuin F, Rascle N, Belibassakis KA (2008) Explicit wave-averaged primitive equations using a generalized Lagrangian mean. Ocean Model 20:235-264

Ardhuin F, Bertotti L, Bidlot JR, Cavaleri L, Filipetto V, Lefevre JM, Wittmann P (2007) Comparison of wind and wave measurements and models in the western Mediterranean Sea. Ocean Eng 34:526-541

Bennis A, Ardhuin F, Dumas F (2011) On the coupling of wave and three-dimensional circulation models: Choice of theoretical framework, practical implementation and adiabatic tests. Ocean Model 40:260-277

Breivik Ø, Mogensen K, Bidlot JR, Balmaseda MA, Janssen PA (2015) Surface wave effects in the NEMO ocean model: forced and coupled experiments. J Geophys Res, Oceans 120:2973-2992

Breivik Ø, Janssen P, Bidlot J (2014) Approximate stokes drift profiles in deep water. J Phys Oceanogr 44(9):2433-2445. doi:10.1175/JPO-D-14-0020.1

Brodeau L (2007) Contribution à l'Amélioration de la Fonction de Forcage des Modéles de Circulation Générale Océanique. Université Joseph-Fourier, Dissertation

Buongiorno Nardelli B, Tronconi C, Pisano A, Santoleri R (2013) High and ultra-high resolution processing of satellite sea surface temperature data over southern European seas in the framework of MyOcean project. Remote Sens Environ 129:1-16

Cavaleri L, Bertotti L (2003) The characteristics of wind and wave fields modelled with different resolutions. Q J R Meteorol Soc 129:1647-1662

Cavaleri L, Fox-Kemper B, Hemer M (2012) Wind waves in the coupled climate system. Bull Amer Meteor Soc 93:1651-1661

Drevillon M, Bourdalle-Badie R, Derval C et al (2008) The GODAE/ MercatorOcean global ocean forecasting system: results, applications and prospects. J Operational Oceanography 1:51-57

Estubier A, Levy M (2000) Quel schema numerique pour le transport d'organismes biologiques par la circulation oceanique. Note Techniques du Pole de modelisation, Institut Pierre-Simon Laplace, p 81

Galanis G, Hayes D, Zodiatis G, Chu PC, Kuo YH, Kallos G (2012) Wave height characteristics in the Mediterranean Sea by means of numerical modeling, satellite data, statistical and geometrical techniques. Mar Geophys Res 33:1-15

Gunther H., Hasselmann H, Janssen PAEM (1993) The WAM model cycle 4. DKRZ report n.4

Hasselmann K (1974) On the characterization of ocean waves due to white capping. Bound-Layer Meteorol 6:107-127

Hasselmann S, Hasselmann K (1985) Computations and parameterizations of the nonlinear energy transfer in a gravity wave spectrum. Part I: a new method for efficient computations of the exact nonlinear transfer integral. J Phys Oceanogr 15:1369-1377

Hasselmann S, Hasselmann K, Allender JH, Barnett TP (1985) Computations and parameterizations of the nonlinear energy transfer in a gravity wave spectrum. Part II: parameterizations of the 
nonlinear energy transfer for application in wave models. J Phys Oceanogr 15:1378-1391

Hellerman S, Rosenstein M (1983) Normal monthly wind stress over the world ocean with error estimates. J Phys Oceanogr 13:93-104

Janssen PAEM (1991) Quasi-linear theory of wind wave generation applied to wave forecasting. J Phys Oceanogr 21:1631-1642

Janssen PAEM (1989) Wave induced stress and the drag of air flow over sea wave. J Phys Oceanogr 19:745-754

Jonsson IG (1990) Wave-current interactions. In: Le Mehaute B, Hanes DM (eds) The sea. Ocean Engineering Science, Wiley, New York, pp 65-120

Kahma KK, Calkoen CJ (1992) Reconciling discrepancies in the observed growth of wind-generated waves. J Phys Oceanogr 22: 1389-1405

Komen GJ, Hasselmann S, Hasselmann K (1984) On the existence of a fully developed windsea spectrum. J Phys Oceanogr 14:1271-1285

Korres G, Papadopoulos A, Katsafados P, Ballas D, Perivoliotis L, Nittis K (2011) A 2-year intercomparison of the WAM-CYCLE4 and the WAVEWATCH-III wave models implemented within the Mediterranean Sea. Mediterr Mar Sci 12(1):129-152

Kumar N, Voulgaris G, Warner JC, Olabarriet M (2012) Implementation of the vortex force formalism in the coupled ocean-atmospherewave-sediment transport (COAWST) modeling system for inner shelf and surf zone applications. Ocean Model 47:65-95

Large W, Yeager S (2004) Diurnal to decadal global forcing for ocean and sea-ice models: the data sets and flux climatologies. CGD NCAR Technical Note: TN-460+STR, pp 111

Large W (2006) Surface fluxes for practitioners of global ocean data assimilation. In: Chassignet E and Verron J (ed) Ocean weather and forecasting, Springer, pp 229-270

Lionello P, Martucci G, Zampieri M (2003) Implementation of a coupled atmosphere-wave-ocean model in the Mediterranean Sea: sensitivity of the short time scale evolution to the air-sea coupling mechanisms. Global Atmos Ocean Syst 9(1-2):65-95

Madec G (2008) NEMO ocean engine. Note du Pole de modélisation, Institut Pierre-Simon Laplace (IPSL), France, Note 27 ISSN 12881619, pp 209

Madec G, Delecluse P, Imbard M, Levy C (1998) OPA version 8.1 ocean general circulation model reference manual. Technical Report, LODYC/IPSL, Note 11, pp 91

Mastenbroek C, Burgers GJH, Janssen PAEM (1993) The dynamical coupling of a wave model and a storm surge model through the atmospheric boundary layer. J Phys Oceanogr 23:1856-1866

McWilliams JC, Restrepo JM, Lane EM (2004) An asymptotic theory for the interaction of waves and currents in coastal waters. J Fluid Mech $511: 135-178$

Mellor GL (2011) Wave radiation stress. Ocean Dyn. doi:10.1007/ s10236-010-0359-2

Mellor GL (2008) The depth-dependent current and wave interaction equations: a revision. J Phys Oceanogr 38:2587-2596

Mellor GL (2003) The three-dimensional current and surface wave equations. J Phys Oceanogr 33:1978-1989
Michaud H, Marsaleix P, Leredde Y, Estournel C, Bourrin F, Lyard F, Mayet C, Ardhuin F (2012) Three dimensional modelling of waveinduced current from the surf zone to the inner shelf. Ocean Sci 8: $657-681$

Miles JW (1957) On the generation of surface waves by shear flows. J Fluid Mech 3:185-204

Oddo P, Adani M, Pinardi N, Fratianni C, Tonani M, Pettenuzzo D (2009) A nested Atlantic-Mediterranean Sea general circulation model for operational forecasting. Ocean Sci 5:461-447

Oddo P, Bonaduce A, Pinardi N, Guarnieri A (2014) Sensitivity of the Mediterranean sea level to atmospheric pressure and free surface elevation numerical formulation in NEMO. Geosci Model Dev 7: 3001-3015

Pacanowsky RC, Philander SGH (1981) Parameterization of vertical mixing in numerical models of tropical oceans. J Phys Oceanogr 11:1443-1451

Pettenuzzo D, Large WG, Pinardi N (2010) On the corrections of ERA-40 surface flux products consistent with the Mediterranean heat and water budgets and the connection between basin surface total heat flux and NAO. J Geophys Res 115:C06022. doi:10.1029/ 2009JC005631

Phillips OM (1977) The dynamics of the upper ocean. Cambridge Univ Press, $\mathrm{p} 336$

Rascle N (2007) Impact of waves on the ocean circulation (impact des vagues sur la circulation océanique). Université de Bretagne Occidentale, Dissertation http://tel.archives-ouvertes. fr/tel-00182250

Smith SD, Banke EG (1975) Variation of the sea surface drag coefficient with wind speed. Quart J Roy Meteorol Soc 101:665-673

Staneva J, Alari V, Breivik Ø, Bidlot JR, Mogensen K (2017) Effects of wave-induced forcing on a circulation model of the North Sea. Ocean Dyn 67(1):81-101

Tolman HL (2009) User manual and system documentation of WAVEWATCH IIITM version 3.14. NOAA/NWS/NCEP/MMAB Tech. Note 276, pp 194

Tolman HL (2002) Validation of WAVEWATCH III version 1.15 for a global domain. NOAA/NWS/NCEP/OMB Technical Note 213, pp 33

Tonani M, Balmaseda M, Bertino L, Blockley E, BrassingtonG DF, Drillet Y, Hogan P, Kuragano T, Lee T, Mehra A, Paranathara F, Tanajura CAS, Wang H (2015) Status and future of global and regional ocean prediction systems. J Operational Oceanography 8 : 201-220. doi:10.1080/1755876X.2015.1049892

Uchiyama Y, McWilliams JC, Shchepetkin AF (2010) Wave-current interaction in an oceanic circulation model with a vortex-force formalism: Application to the surf zone. Ocean Model 34:16-35

Van Leer B (1979) Towards the ultimate conservative difference scheme. V A Second Order Sequel to Godunov's Method J Comp Phys 32: 101-136

Wu J (1982) Wind-stress coefficients over sea surface from breeze to hurricane. J Geophys Res 87:9704-9706

Wu J (1980) Wind-stress coefficients over sea surface near neutral conditions: a revisit. J Phys Oceanogr 10:727-740 